\title{
Proteins involved in maturation pathways of plant mitochondrial and plastid $c$-type cytochromes
}

\author{
Michal Rurek ${ }^{\bowtie}$ \\ Department of Molecular and Cellular Biology, Institute of Molecular Biology and Biotechnology, Faculty of \\ Biology, Adam Mickiewicz University, Poznań, Poland
}

Received: 14 August, 2007; revised: 11 July, 2008; accepted: 31 July, 2008

available on-line: 04 September, 2008

\begin{abstract}
$c$-Type cytochromes are characterized by the presence of two covalent bonds linking heme to apocytochrome and by the heme attachment motif in the apoprotein. Several molecular systems for the maturation of $c$-type cytochromes have evolved in different organisms. The best characterized are three of them: system I, system II and system III. Heme is synthesized in bacterial cytoplasm, in plastids, and in animal and fungal mitochondria. Therefore the maturation of bacterial and plastid $c$-type cytochromes involves the transport of heme and apocytochrome from the $n$ side to the $p$-side of the respective biological membranes and the formation of the covalent bond at the $p$-side. It should be underlined that the site of the $c$-type apocytochrome synthesis is also distinct from the site of its functioning. The aim of this review is to present the current state of knowledge concerning the structure and function of two systems - system I and system II - in the maturation of plant mitochondrial and plastid $c$-type cytochromes, respectively.
\end{abstract}

Keywords: c-type cytochromes, plant mitochondria, plastids, cytochrome $c$ maturation proteins, protein-protein interactions

\section{INRODUCTION}

c-Type cytochromes are ubiquitous proteins playing an important role in almost all cells. They are present in different compartments and participate in various biochemical pathways, such as respiration, photosynthesis and apoptosis (Kranz et al., 1998; Turkarslan et al., 2006). A vast number of $c$-type cytochromes, e.g. cyt. $c$, cyt. $c_{1}$, cyt. $c^{\prime}$ and cyt. $c_{4}$, are present in bacteria, where they participate in electron transfer and catalysis, especially in nitrogen metabolism (Ferguson, 2001; Allen et al., 2004a). c-Type cytochromes are also present in plant and animal cells.

The main feature of $c$-type cytochromes is the presence of a covalent bonds between heme vinyls and apoprotein cysteine thiol groups (Fig. 1). For the covalent bond formation, $c$-type apocytochromes require the conserved sequence $\mathrm{CXXCH}$, which is a consensus heme-binding motif known as the $c$-type

\footnotetext{
${ }^{\square}$ Corresponding author: Michal Rurek, Department of Molecular and Cellular Biology, Institute of Molecular Biology and Biotechnology, Faculty of Biology, A. Mickiewicz University, Umultowska 89, 61-614 Poznan, Poland; phone: (48 61) 829 5968; fax: (48 61) 829 5949; e-mail: rurek@amu.edu.pl

Abbreviations: ABC, ATP-binding cassette; Bdb, Bacillus disulfide bond formation; BdbCD, disulfide oxidases in SII; ccb, cytochrome $c$ biogenesis; ccd, cytochrome $c$ defective; CCDA, disulfide reductase in plant SII; CCHL, cytochrome $c$ heme lyase; $\mathrm{CC}_{1} \mathrm{HL}$, cytochrome $c_{1}$ heme lyase; $\mathrm{Ccm}$, cytochrome $c$ maturation; $\mathrm{CcmABCD}$, components of transporting complex in prokaryotic SI; CcmE, heme chaperon; $\mathrm{CcmF}$, heme lyase component; $\mathrm{CcmG}$, periplasmic thioredoxin-like protein; $\mathrm{CcmH}$, disulfide reductase; CcmI, component of Rhodobacter SI; Ccs, cytochrome $c$ synthesis; CcsAB, proteins responsible for heme delivery in SII; Ccs1, plant homolog of prokaryotic CcsB protein; $\mathrm{CycH}(\mathrm{L}), \mathrm{CcmH}$ protein homologs; Cyc2p, accesory protein in fungal SIII; cyt., cytochrome; Dip, disulfide-isomerase-like protein; Dsb, disulfide bond formation protein; DsbAB, disulfide oxidases in prokaryotic SI; DsbD, disulfide reductase in prokaryotic SI; Erv, essential for respiration and vegetative growth; Fd, ferredoxin; FTR, ferredoxin-thioredoxin reductase; HCF, high chlorophyll fluorescence phenotype; HL, heme lyase; holocyt., holocytochrome; IMS, intermembrane space of mitochondria; OM/ IM, mitochondrial outer/ inner membrane; ORF, open reading frame; Mia, mitochondrial import and assembly; $n / p$-side, negatively/ positively charged membrane side; pet, plastid gene encoding cytochrome $f$; ResBC, components of prokaryotic SII; SI, system I; SII, system II; SIII, system III; Sec, general secretory pathway; Trx(s), thioredoxin(s).
} 

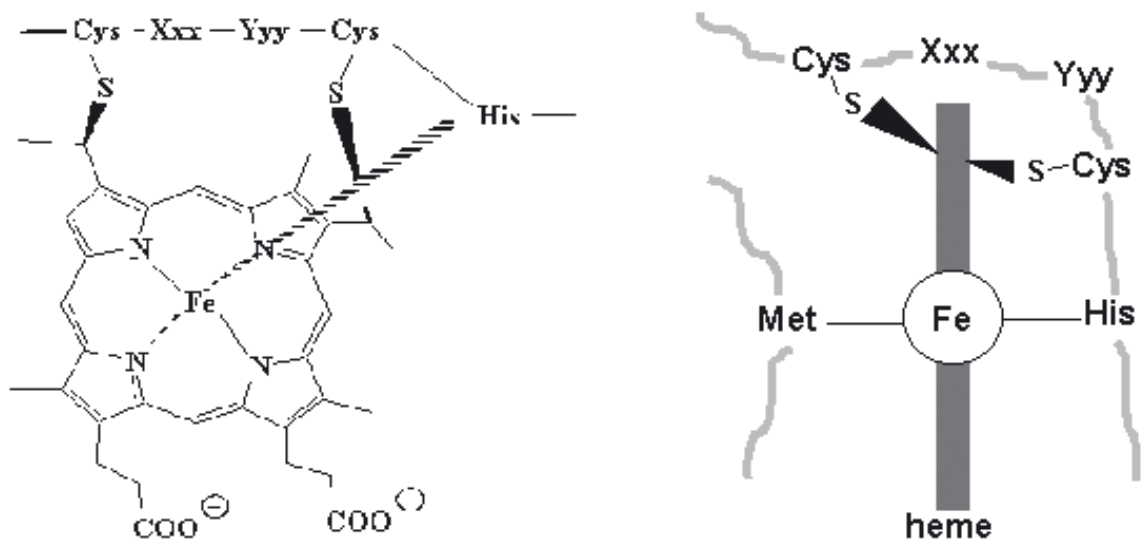

Figure 1. Covalent bonds linking heme and c-type apocytochromes.

After Giegé et al. (2008) and Allen et al. (2008), modified.

cytochrome signature. The two cysteine thiols of this sequence are covalently linked with the vinyl side chains of heme. Stevens et al. (2004) pointed out that the high chemical and thermal stability of c-type cytochromes may be the main reasons of their evolutionary success. $c$-Type cytochromes expose their functional domain outside the bacterial cytoplasmic membrane to the mitochondrial inner membrane space (IMS) or to the thylakoid lumen (Giegé et al., 2008).

The catalytic ligation of heme to apocytochrome $c$ is the heart of the maturation pathways. This is a multistep process, mainly because the sites of heme and apoprotein synthesis and their functioning are different. The maturation of bacterial and plastid c-type cytochromes involves the transport of heme and apocytochrome from the $n$-side to the $p$ side of the plasma membrane and thylakoid membrane, respectively. The formation of the covalent bond proceeds at the $p$-side (i.e., in the periplasmic space or in the thylakoid lumen), where prior to the ligation of heme with apocytochrome $c$, reduction of those components is necessary. For the maturation of mitochondrial c-type cytochromes, the nuclearencoded apocytochrome $c$ is transported from the cytoplasm and heme biosynthesis proceeds either in mitochondria (fungi, animals) or in plastids. Maturation of c-type cytochromes could be treated as a model of post-translational protein modifications (Turkarslan et al., 2006). It should also be noted that this process requires participation of numerous proteins for its full activity.

Despite the great progress in the last 10 years, our knowledge about the pathways of c-type cytochrome maturation in the plant cell is still unsatisfactory. A few reviews concerning the progress in the elucidation of the c-type cytochrome maturation deal mainly with bacterial systems. Only one review of Nakamoto et al. (2000) concerns the maturation of plastid c-type cytochromes and the one by Giegé et al. (2008) characterizes the cytochrome $c$ maturation in mitochondria of various organisms. Hence, the aim of the present review is to provide characteristics of the proteins involved in c-type cytochrome maturation pathways in plant mitochondria and plastids. Moreover, the reader will find relevant data concerning recent proteomic results obtained from the study of the maturation of $c$-type cytochromes.

\section{GENERAL VIEW OF c-TYPE CYTOCHROME MATURATION SYSTEMS}

\section{Components of the maturation pathways and their variability}

It is well known that the number of components necessary for the maturation of $c$-type cytochromes varies among different organisms. Three molecular systems are mainly in action (Kranz et al., 1998; Turkarslan et al., 2006; Feissner et al., 2006a): system I (SI), system II (SII) and system III (SIII). SI is present in $\alpha$ - and $\gamma$-proteobacteria, deinococci, plant and some protozoan mitochondria. SII was found in some Gram positive bacteria, cyanobacteria, plastids, archaeobacteria and some $\beta-, \delta$ - and $\varepsilon$ proteobacteria, while SIII is present in mitochondria of fungi, animals and surprisingly, in some green algae, apicomplexa and protozoa. Recently, Allen et al. (2008) speculated that SI is more ancient than SIII and was presumably present in the proto-mitochondrial endosymbiont; moreover, the main component of SIII - heme lyase (HL) - has replaced SI in many evolutionary lineages.

Each maturation system contains different functional modules, responsible for every step of the maturation process. They are depicted in Fig. 2. and briefly described below.

- The current model for the translocation of apocyt. $c$ in prokaryotic SI and SII involves the ac- 

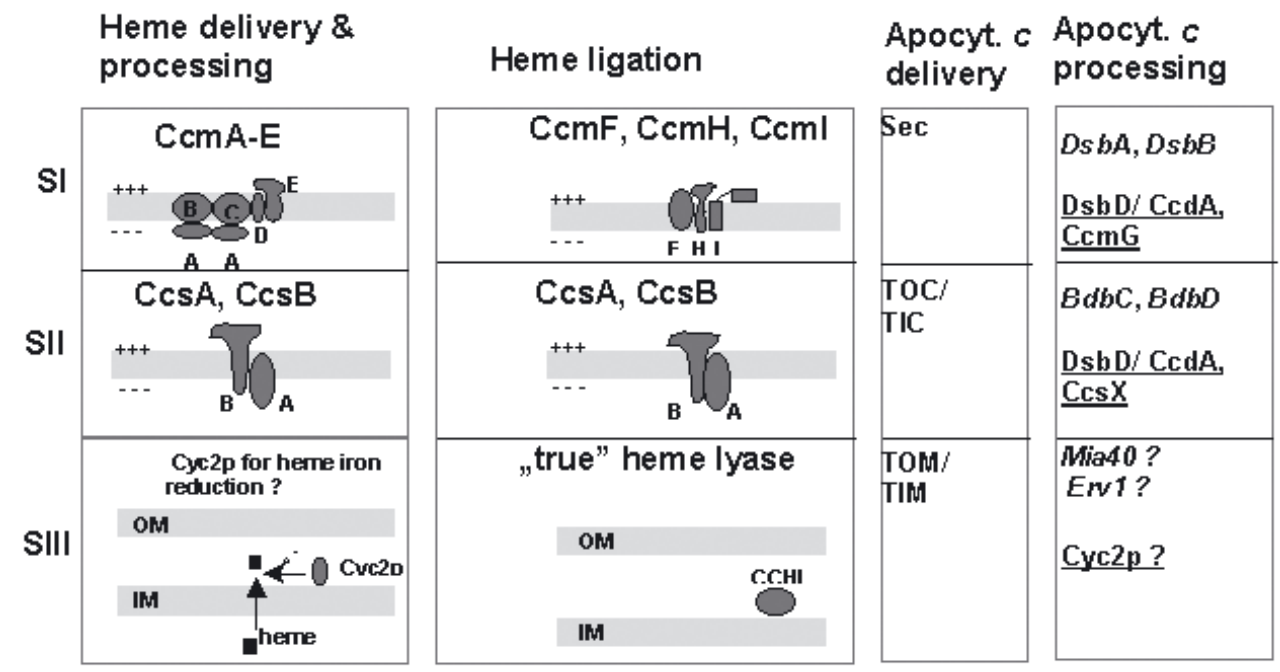

Figure 2. Comparison of the molecular components of different $c$-type cytochrome maturation systems.

After Turkarslan et al. (2006), modified. Details are described in chapter "Components of the maturation pathways and their variability". The $c$-type cytochrome maturation process includes heme and apocytochrome translocation and their processing prior to ligation. The negative side of the membrane, known as $n$-side, refers to the cytoplasm in bacteria and eukaryotic cells, matrix in mitochondria and stroma in plastids. The positive side of the membrane $-p$-side - is topologically equivalent to the periplasm in Gram negative bacteria, cell outside in Gram positive bacteria, IMS in mitochondria and thylakoid lumen in plastids. Components responsible for apocyt. $c$ thiooxidation are shown in italics. Proteins responsible for apocytochrome thioreduction are underlined.

tion of the Sec system, but the TOM complex is engaged in yeast SIII (Diekert et al., 2001). Transport of apocyt. $c_{1}$ to the yeast mitochondria, unlike that of apocyt. $c$, is potential-independent; after crossing $\mathrm{OM}$ and IM with the participation of the TOM and TIM complexes, apocyt. $c_{1}$ is redirected across IM. This is due to the fact that apocyt. $c_{1}$ contains two mitochondrial targeting signals functioning during the transport (Nicholson et al., 1989). Recently, Giegé et al. (2008) speculated that one of the plant mitochondrial CCM proteins (from $\underline{c y t o c h r o m e ~} \underline{c} \underline{\text { matu- }}$ ration) - $\mathrm{CCMH}$, might theoretically be involved in the import of apocyt. $c$. This would need to be confirmed experimentally by studying potential interactions between $\mathrm{CCMH}$ and apocyt. $c$ during the protein import into mitochondria. It should be noted that the proposed function is not the main one ascribed to CCM proteins (see below).

- Genetic analyses of mutants lacking c-type cytochromes has led to the discovery that SI utilizes CcmA-E proteins for heme delivery (reviewed by Giegé et al., 2008). In the case of SII - CcsAB proteins are engaged in this process (see chapter "Proteins participating in heme transport and chaperoning"). It has been noticed that in the case of SIII the last steps of heme synthesis occur at the matrix side of animal and yeast mitochondria IM with the participation of protoporphyrin IX ferrochelatase. The proteins involved in the heme transport across mitochondrial IM in yeast or animal SIII are unknown, but the translocation could be achieved either by a flippase-like enzyme or it may be based on diffusion (Giegé et al., 2008).
- No specific molecular factor reducing the heme iron has been described until now for SI and SII. It is known that yeast SIII utilizes the accessory flavoprotein Cyc2p for that. In addition Bernard et al. (2005) showed that Cyc2p indirectly promotes the CCHL-dependent ligation of apocyt. $c_{1}$ and $c$ with heme. On the basis of the observations of yeast mutant strains defective in the assembly of cytochrome c, Bernard et al. (2005) suggested that yeast Cyc2p may control the redox status of the ligation reaction acting as a heme reductase and/or apocytochrome disulfide reductase (see below).

- The oxidation and reduction of apocytochrome thiols at the $p$-side of the membrane prior to ligation with heme may require the following proteins: in the case of SI - DsbAB for the thioxidation, and for the thioreduction - DsbD and $\mathrm{CcmG}$; in the case of SII - BdbCD proteins probably act for the thiooxidation and DsbD and CcdA - for the thioreduction. The participation of those proteins in such processes was proposed mainly on the basis of the experimental work done on bacterial mutants defective in the c-type cytochrome assembly. In yeast SIII the only known hypothetical candidates are Mia40 and Erv1 for thiooxidation (Turkarslan et al., 2006) and Cyc2p for thioreduction of apocyt. $c$ (Bernard et al., 2005). Their involvement in these processes still requires clear experimental evidence. It is also known that the yeast sulfhydryl oxidase Erv1 mediates the oxidation of redox-regulated receptor Mia40 which oxidizes other proteins (Hell, 2008). 
- One may only speculate that in plant mitochondria, similarly to the bacterial periplasm, ligation is most probably catalyzed by a complex containing orthologs of bacterial $\mathrm{CcmF}$ and $\mathrm{CcmH}$ proteins. Plastid SII may utilize CcsAB proteins for that process. The 'real' HL, which catalyzes the ligation of heme to the c-type apocytochromes, was identified in yeast and animal SIII. Dictyostelium and animal mitochondria contain only a single form of $\mathrm{HL}$, whereas two isoforms are found in yeast (Allen et al., 2008). The two $c$-type apocytochrome-specific heme lyases operating in yeast and Neurospora crassa mitochondria are named $\mathrm{CCHL}$ and $\mathrm{CC}_{1} \mathrm{HL}$. In the absence of $\mathrm{CC}_{1} \mathrm{HL}$, the yeast CCHL heme lyase is active both in the maturation of cyt. $c_{1}$ and of cyt. $c$. The yeast $\mathrm{CC}_{1} \mathrm{HL}$ activity towards apocyt. $c_{1}$ is enhanced by elevated CCHL expression or by point mutations in apocyt. $c_{1}$ or in CCHL. In contrast, yeast $\mathrm{CC}_{1} \mathrm{HL}$ seems to be engaged only in the maturation of cyt. $c_{1}$ (Bernard et al., 2003). The CCHL and $\mathrm{CC}_{1} \mathrm{HL}$ lyases contain one to three characteristic $\mathrm{CPX}$ motifs (where $\mathrm{X}$ represents $\mathrm{V}, \mathrm{H}, \mathrm{I}, \mathrm{L}$ or S) in their N-terminal regions (Steiner et al., 1996).

Some organisms display interesting modifications in the presence and composition of maturation systems. In the mosquito Anopheles gambiae, where the main components of all maturation systems are present, some proteins of SI are absent. Genome analyses have revealed that the prokaryote Bordetella branchioseptica and Desulfitobacterium hafniense may contain some components of SI and SII. A modified $\mathrm{Ccm}$ protein apparatus is present in Archaeobacteria and Desulfovibrio. Allen et al. (2006) - on the basis of in silico searches - pointed out that it probably does not include $\mathrm{CcmH}$; additionally, CcmE contains an altered heme-binding motif CXXXY instead of HXXXY known for Escherichia coli. It is tempting to speculate that archaea may contain extremely divergent $\mathrm{Ccm}$ proteins. Since our knowledge about the components of plant SI and SII is still limited, one could also expect the discovery of novel protein factors indispensable for the assembly process of $c$-type cytochromes.

Surprisingly, a distinct form of apocyt. $c$ is present in free-living kinetoplastids (Trypanosoma, Leishmania), Euglena and in the flagellate Diplonema papillatum. It contains $\mathrm{AX}_{2} \mathrm{CH}$ or $\mathrm{FX}_{2} \mathrm{CH}$ motifs. This implies that such $c$-type cytochromes have only one thioether bond between heme and the apoprotein (Allen et al., 2008). Since there is no experimental evidence that any elements of the common maturation systems are encoded in the nuclear or mitochondrial genomes of those organisms, Allen et al. (2004b) suggested that a distinct maturation routes of apocyt. $c_{1}$ and apocyt. $c$ may exist.

In plant cells only a limited number of monoheme cytochromes is present. It seems that bacteria containing more monoheme and additionally some multiheme cytochromes, have gained a broader adaptability to environmental conditions. Unlike in plants, in bacterial cells there are various forms of the respiratory chain. The presence of various monoheme proteins in prokaryotic cells may be a consequence of the evolutionary development of the particular system of maturation. It is evident that different organisms and organelles utilize various systems for the maturation of $c$-type cytochromes, characterized by broad complexity and sometimes quite a surprising composition (Allen et al., 2003; Stevens et al., 2004). One may conclude that the potential new molecular systems for the maturation of diverse $c$-type cytochromes are awaiting characterization.

\section{Utilization of different maturation pathways}

What is the substrate specificity of the different systems of c-type cytochrome maturation? It was shown that SI of eubacteria expressed from constructs containing $\mathrm{ccm}$ genes could be involved in the maturation of a wide variety of $c$-type cytochromes (Allen \& Ferguson, 2006). Recent findings indicate that heme levels may discriminate the participation of SI and SII in the maturation of c-type cytochromes. Engineered E. coli strains producing recombinant SI used fivefold lower heme concentrations than those using SII from Helicobacter pylori, which is more abundant in heme. None of the known c-type cytochrome maturation systems uses non-iron-protoporphyrins for the maturation; they sometimes display even an inhibitory effect on the maturation of cyt. $c$ (Richard-Fogal et al., 2007). Feissner et al. (2006a) speculated that low endogenous heme levels could promote the evolution of SI. Moreover, they pointed out that SII has a lower affinity for heme than SI, and therefore SII may require a higher heme concentration to assemble cyt. $c$ than SI.

It was also shown that in a Ccm knocked-out strain of $E$. coli, SI could be entirely replaced by a fused CcsB-CcsA protein of H. pylori SII (Feissner et al., 2006b). This means that at least heme delivery and periplasmic ligation are interchangeable between the two c-type cytochrome maturation systems in Prokaryota. However, system II lacks some vital elements of system I, for example the heme chaperone known as the $\mathrm{CcmE}$ protein (Feissner et al., 2006b). Moreover, SI contains an associated $A B C$ transporter that could transport heme present at a low concentration (Goldman et al., 1998; Kranz et al., 1998). Thus, the maturation pathway of distinct c-type cytochromes seems to be more flexible in SII than in SI. 


\section{c-TYPE CYTOCHROMES IN PLANT MITOCHONDRIA AND PLASTIDS}

Plant mitochondria contain two c-type cytochromes present in the respiratory chain, both encoded in the nuclear genome: cyt. $c_{1}$ and cyt. $c$. A common feature of all $c$-type cytochromes is the prevalence of $\alpha$-helical regions. Plastidal cyt. $f$, composed almost entirely of $\beta$-sheet barrels, is the only exception (Stevens et al., 2004).

As regards plastids, cyt. $f$ is encoded by the plastid petA gene (however, nuclear in Euglena) and cyt. $c_{6}-$ by the nuclear $C y c 6$ gene. The latter is - in Chlamydomonas - known to be transcribed during abiotic stress conditions, namely in response to copper deficiency and during hypoxia (Quinn et al., 2000). Cyt. $c_{6}$ represents a soluble cytochrome, found only in cyanobacteria and algae (Nakamoto et al., 2000). Recently, a novel c-type cytochrome cytochrome $c_{6}$-like (known also as cyt. $c_{x}$ ) was discovered in the plastid lumen of vascular plants and green algae (Weigel et al., 2003; Howe et al., 2006). It appeared that Chlamydomonas plastids contain both cyt. $c_{6}$ and cyt. $c_{6}$-like. The structural data of Arabidopsis cyt. $c_{6}$-like show that its surface properties are different from those of plastocyanin. Therefore, it is believed (Howe et al., 2006) that cyt. $c_{6}$-like, unlike cyt. $c_{6}$, cannot serve as a simple substitute for plastocyanin.

\section{PROTEIN SYSTEM FOR THE MATURATION OF $c$-TYPE CYTOCHROMES IN PLANT MITOCHONDRIA}

Plant mitochondria follow the pathway of SI for the maturation of $c$-type cytochromes, which resembles the system of $\alpha$-proteobacteria and which is distinct from the fungal and animal SIII. The essential features of SI based on prokaryotic data are presented in Fig. 3.

Lee et al. (2007) have suggested that duplications, deletions and fusions of transmembrane segments occurred during evolution of some SI proteins, like $\mathrm{CcmC}$ and $\mathrm{CcmF}$ as well as $\operatorname{ResC}$, the member of SII. Nevertheless, there is similarity in the structure among those components of the two maturation systems as they have evolved from an ancestor protein containing six putative transmembrane segments.

Terminology, organization and expression of genes encoding plant mitochondrial components of system I

The initial terminology of genes encoding components of the plant mitochondrial system I was based on the bacterial gene homologs. Currently they are frequently called $\mathrm{ccm}$ (from cytochrome $c$ maturation). This term has replaced the previous one - ccb (from cytochrome $c$ biogenesis) used for

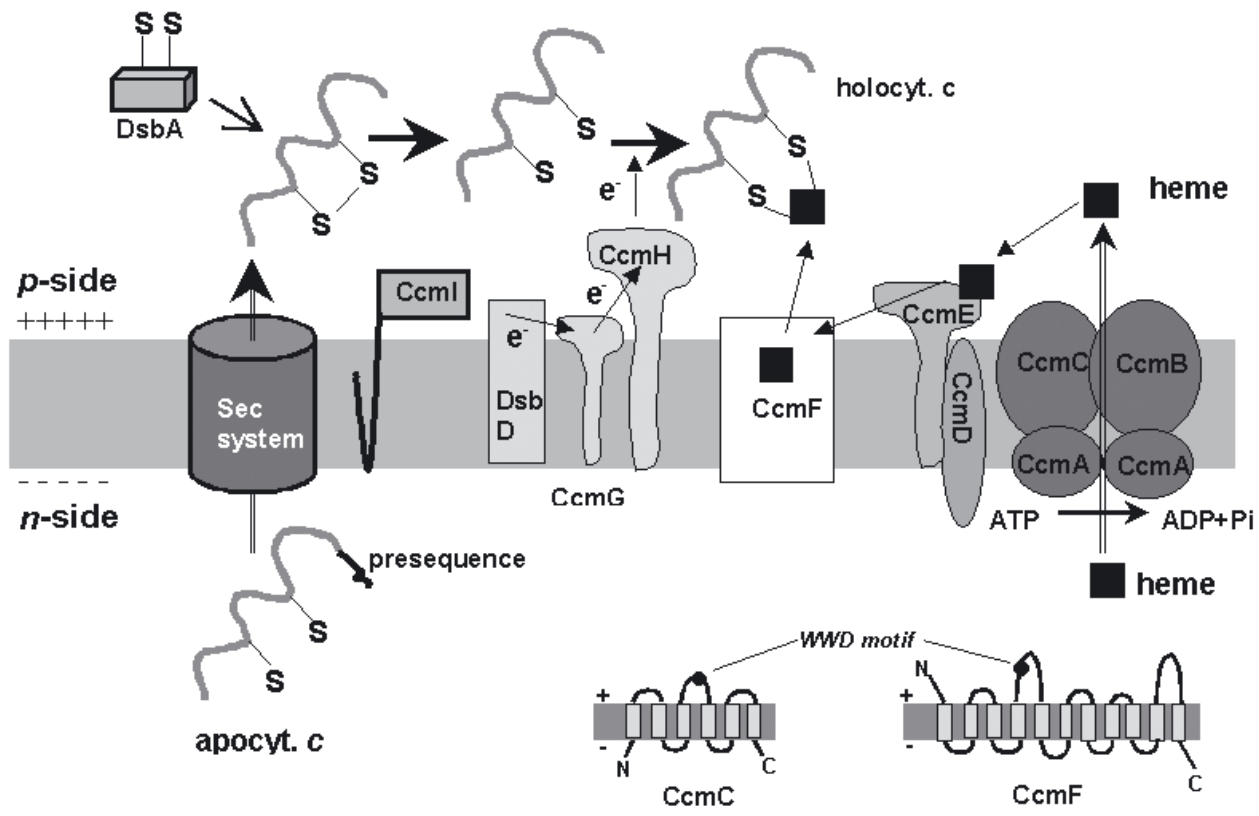

Figure 3. Model for system I of $c$-type cytochrome biogenesis based on prokaryotic data.

After Feissner et al. (2006b), modified. Detailed description of the presented pathways is provided in chapters "Components of the maturation pathways and their variability", "Proteins participating in heme transport and chaperoning", "Thiooxidation/thioreduction pathway" and "Components of system I responsible for the heme lyase activity". Apocytochrome import is shown at the left, the thioreduction pathway in the middle and heme translocation and delivery route at the right. Topology of bacterial $\mathrm{CcmC}$ and $\mathrm{CcmF}$ proteins with the localization of the WWD motif is also shown. 
mitochondrial genes. Plant mitochondrial proteins necessary for the maturation pathway of $c$-type cytochromes are known as CCM proteins. $\mathrm{CcmB}, \mathrm{CcmC}$, $\mathrm{CcmF}_{\mathrm{c}^{\prime}} \mathrm{CcmF}_{\mathrm{N} 1}$ and $\mathrm{CcmF}_{\mathrm{N} 2}$ proteins are encoded in the Arabidopsis thaliana mitochondrial genome, while CCMA, CCMH and CCME proteins - in the nucleus. The different terminology systems of $c$-type cytochrome maturation genes are summarized in Table 1.

Notably, the plant $c c m F$ gene is divided into distinct ORFs encoding the N- $\left(\mathrm{ccmF}_{N}\right)$ and C- $(\mathrm{ccm}-$ $\left.F_{C}\right)$ terminal domains of the protein; in Brassica napus and Arabidopsis mitochondria, $c c m F_{N}$ ORF is further divided into $c c m F_{N 1}$ and $c c m F_{N 2}$. In B. napus 'Polima' those genes are located on two separate subgenomic molecules (Menassa et al., 1997). On the other hand, mitochondrial DNA of Nicotiana tabacum, Beta vulgaris and Oryza sativa contains a single $c c m F_{N}$ gene. The $c c-$ $m F_{C}$ gene is present in all mitochondrial genomes of Embryophyta investigated so far. In the mitochondrial genome of Marchantia polymorpha, though, it is divided into two separate genes: $c c m F_{C 1}$ and $c c m F_{C 2}$.

The organization of $\mathrm{ccm}$ genes in different mitochondrial genomes is variable because of their evolutionary shuffling and splitting in the course of recombination.

For instance, the $c c m F_{N}$ and $c c m F_{C}$ genes in $B$. vulgaris and $O$. sativa, $c c m F_{C}$ and $c c m B$ in Tripsacum

Table 1. Terminology of genes encoding components of cytochrome $c$ biogenesis system I

\begin{tabular}{|c|c|c|c|c|c|c|c|c|c|}
\hline & E. c. & B. $j$. & R. c. & R. a. & C. $m$. & M. $p$ & O. $b$. & A. t., B. n. & $\begin{array}{l}\text { B. v., N.t., } \\
\text { O. s., S. b., } \\
\text { B. v., } \\
\text { T. a., T. d., } \\
\text { Z.m. }\end{array}$ \\
\hline & ccmA & $c y c V$ & helA & yejW & yejW & & & $\begin{array}{l}\text { A. t. CCMA } \\
\text { (nuclear) }\end{array}$ & \\
\hline & $c c m B$ & $\operatorname{cycW}$ & helB & yejV & yejV & $\operatorname{orf} 277$ & orf 206 & $\begin{array}{l}c c m B(c c b 2, \\
c c b 206)\end{array}$ & ccmB (orf206) \\
\hline & $\mathrm{ccm} C$ & $c y c Z$ & helc & yeju & yeju & orf 228 & $\operatorname{orf} 250$ & $\begin{array}{l}c c m C(c c b 3, \\
c c b 256)\end{array}$ & $\begin{array}{l}\operatorname{ccm} C(\text { orf } 240) ; \\
(\text { B. v.-3' orf518) }\end{array}$ \\
\hline & $c c m D$ & $\operatorname{cyc} X$ & helD & & & & & & \\
\hline & $c c m E$ & $c y c J$ & & & & & & $\begin{array}{l}\text { A. t. CCME } \\
\text { (nuclear) }\end{array}$ & \\
\hline & $c c m F$ & cycK & ccl1 & ccl1 & yejR & & & & \\
\hline & & & & & & $\begin{array}{l}\operatorname{ccm}_{N} \\
(\operatorname{orf509})\end{array}$ & $\begin{array}{l}c c m F_{N} \\
\text { (orf577) }\end{array}$ & $\begin{array}{l}\operatorname{ccmF}_{N 1} \\
(c c b 6 n 1, c c b 382) \\
c c m F_{N 2} \\
(c c b 6 n 2, c c b 203)\end{array}$ & $\begin{array}{l}c c m F_{N} \\
(c c b 574, \text { orf589) }\end{array}$ \\
\hline & & & & & & $\begin{array}{l}\operatorname{ccm}_{\mathrm{C1}} \\
\left(\operatorname{orf169}_{16}\right) \\
\text { ccmF }_{\mathrm{C} 2} \\
(\operatorname{orf322})\end{array}$ & $\begin{array}{l}c c m F_{C} \\
\text { (orf } 454)\end{array}$ & $\begin{array}{l}c c m F_{C} \\
(c c b 6 c, c c b 452)\end{array}$ & $\begin{array}{l}c c m F_{C} \\
(c c b 438, \text { orf437) }\end{array}$ \\
\hline & $\mathrm{ccm} G$ & $\operatorname{cyc} Y$ & helX & & & & & & \\
\hline & $\mathrm{ccmH}$ & $c y c L$ & ccl2 & & & & & $\begin{array}{l}\text { A. t. CCMH } \\
\text { (nuclear) }\end{array}$ & \\
\hline $\begin{array}{l}\text { Main re- } \\
\text { ferences }\end{array}$ & $\begin{array}{l}\text { Thöny- } \\
\text { Meyer, } \\
\text { et al. } \\
\text { (1995) }\end{array}$ & $\begin{array}{l}\text { Ramse- } \\
\text { ier et al. } \\
\text { (1991), Ritz } \\
\text { et al. (1995) }\end{array}$ & $\begin{array}{l}\text { Beckman } \\
\text { et al. } \\
(1992)\end{array}$ & $\begin{array}{l}\text { Lang } \\
\text { et al. } \\
\text { (1997) }\end{array}$ & $\begin{array}{l}\text { Ohta et } \\
\text { al. (1998) }\end{array}$ & $\begin{array}{l}\text { Oda et al. } \\
(1992)\end{array}$ & $\begin{array}{l}\text { Schuster et } \\
\text { al. (1993), } \\
\text { Jekabsons } \\
\text { \& Schuster } \\
\text { (1995) }\end{array}$ & $\begin{array}{l}\text { Unseld et al. } \\
\text { (1997), Handa } \\
\text { (2003), Giegé } \\
\text { \& Brennicke } \\
\text { (1999), Raya- } \\
\text { puram et al. } \\
\text { (2007), Spie- } \\
\text { lewoy et al. } \\
\text { (2001), Meyer } \\
\text { et al. (2005) }\end{array}$ & $\begin{array}{l}\text { Kubo et al. } \\
(2000), \text { Su- } \\
\text { giyama et al. } \\
\text { (2005), Notsu } \\
\text { et al. (2002), } \\
\text { Ogihara et al. } \\
\text { (2005), Clifton } \\
\text { et al. (2004), } \\
\text { Gonzalez et } \\
\text { al. (1993), } \\
\text { Bonnard \& } \\
\text { Grienenberger } \\
\text { (1995) }\end{array}$ \\
\hline
\end{tabular}

The included species are: $\alpha$ proteobacteria: Bradyrhizobium japonicum (B. j.) and Rhodobacter capsulatus (R. c.); $\gamma$ proteobacterium Escherichia coli (E. c.); the protist Reclinomonas americana (R. a.) and the following plant representatives: Cyanidioschyzon merolae (C. m.), Marchantia polymorpha (M. p.), Arabidopsis thaliana (A. t.), Triticum aestivum (T. a.), Brassica napus (B. n.), Oenothera berteriana (O. b.), Beta vulgaris (B. v.), Oryza sativa (O. s.), Nicotiana tabacum (N. t.), Sorghum bicolor (S. b.), Tripsacum dactyloides (T. d.) and Zea mays (Z. m.). 
dactyloides, $c c m B$ and $c c m F_{N}$ in Zea luxurians, $c c m F_{C}$ and $\mathrm{ccmC}$ in Cycas taitungensis and all $\mathrm{ccm}$ genes in M. polymorpha and Physcomitrella patens mitochondrial genomes are located close to one another. The $T$. dactyloides and $Z$. luxurians $c c m F_{C}$ gene, $T$. dactyloides $\mathrm{ccmF}_{N}$ gene or Oenothera bertheriana and Daucus carota $\mathrm{ccmB}$ and $\mathrm{ccmF}$ genes are duplicated (Schuster et al., 1993; Schuster, 1994).

The transfer of mitochondrial $\mathrm{ccm}$ genes to the nucleus represents one of the known phenomena connected with the evolution of organellar genomes. E. coli $\mathrm{ccm}$ genes are clustered in a single operon: c $C M A B C D E F G H$; however, during the acquisition of the mitochondrial ancestor by the eukaryotic cell, the operon was shuffled by recombination; some $\mathrm{ccm}$ genes were transferred to the nucleus (ThönyMeyer et al., 1995). The nuclear CCMA and CCME plant genes are transcribed at a low, but detectable level in roots, rosette leaves, stems, stem leaves and flowers of Arabidopsis (Spielewoy et al., 2001; Meyer et al., 2005; Rayapuram et al., 2007).

Some surprising data concerning the plant mitochondrial $\mathrm{ccm}$ gene transcription came from the analysis of the structure and expression of the $c \mathrm{~cm} F_{N 1}$ and $\mathrm{ccmF}_{\mathrm{N} 2}$ genes. For Brassica mitochondria, where despite the distinct transcriptional units the two ORFs the $\mathrm{CcmF}_{\mathrm{N}}$ protein is present, Handa et al. (1996) proposed, without any conclusive experiment, that either so called 'ribosome hopping' or protein trans-splicing are responsible for that phenomenon. However, up to now no decisive experimental data supporting one of the proposed views has been published.

The mitochondrial $\mathrm{ccm}$ transcripts are among the most extensively edited plant mitochondrial mRNAs (Giegé \& Brennicke, 1999). Recently, Hazle and Bonen (2007) examined in silico the $5^{\prime}$ UTRs of different protein-coding mitochondrial genes of a few flowering plants in order to identify the essential sequence features related to the initiation of translation. The maize and wheat $c c m F_{N}$ gene transcripts may utilize only the proximal (out of two putative ones) start codon for the translation. The mature $\mathrm{ccm}$ transcripts may also be interrupted before stop codons, like in the case of Brassica ccm $\mathrm{C}$ mRNA (Handa, 2003). Moreover, such interrupted Arabidopsis and cauliflower $\mathrm{ccm} C$ transcripts were translated. The CcmC protein which accumulates in Arabidopsis mitochondria is therefore truncated by only few less important residues (Raczynska et al., 2006).

\section{Proteins participating in heme transport and chap- eroning}

The heme delivery in SI is probably connected with the activity of a few proteins CCMA-E: in plants the best characterized are: $C \mathrm{CMA}, \mathrm{CmB}$, $\mathrm{CcmC}$ and CCME.
It is difficult to describe precisely the function of each of these proteins in plant mitochondria because of the limited experimental data and due to the fact that the vast majority of published data concerning the functionality of SI bases on prokaryotic models. Moreover, plant CCM proteins are of highly hydrophobic and low-abundant. There are suggestions that in the prokaryotic $\mathrm{SI}$, the $\mathrm{CcmA}$, $\mathrm{CcmB}, \mathrm{CcmC}$ and $\mathrm{CcmD}$ proteins form a transporter complex which contains an ATP-binding cassette. Nevertheless, it is still under discussion whether prokaryotic $\mathrm{Ccm} A B$ proteins are really required for the translocation of heme across the cytoplasmic membrane (Goldman \& Kranz, 2001; Feissner et al., 2006a; Christensen et al., 2007). It has been shown that membrane vesicles depleted of CcmA display an efficient heme uptake. From those experiments one may conclude that $\mathrm{CcmA}$ and $\mathrm{CcmB}$ proteins may not be necessary for heme transport through the membrane and their real transported ligand remains to be identified (Cook \& Poole, 2000).

The globular CcmA polypeptide belongs to the classical ATP-binding protein family because it contains the Walker A $\left(\mathrm{GX}_{4} \mathrm{GKS} / \mathrm{T}\right)$ and Walker $\mathrm{B}\left(\mathrm{R} / \mathrm{KX}_{3} \mathrm{GX}_{3} \mathrm{LX}_{3} \mathrm{D}\right)$ motifs (Walker et al., 1982) and the $A B C$ signature unique to $A B C$ transporters. Mutation in this motif may result in a total loss of cytochrome $c$ maturation efficiency in vivo (Christensen et al., 2007). Some minor differences between bacterial and plant CCMA orthologs were discovered (Rayapuram et al., 2007). The plant CCMA protein was immunodetected at a low level in Arabidopsis cell cultures, roots, leaves and flower mitochondria (Rayapuram et al., 2007). This suggests its housekeeping function. A striking feature of the plant CCMA protein is the presence of a short $\mathrm{N}$ terminal extension without properties of a typical mitochondrial targeting $\alpha$-helical sequence. Nevertheless, CCMA is imported into cauliflower mitochondria in a membrane-potential dependent way. Rayapuram et al. (2007) also showed that CCMA is associated with the inner membrane and oriented towards the matrix and this association could be modulated by the binding and hydrolysis of ATP, inducing a conformational change in the protein. Therefore the Arabidopsis CCMA protein has properties of the ATP-binding domain of the ABC transporter, like its prokaryotic homolog. The authors also identified a $480-\mathrm{kDa}$ complex containing CCMA in the Arabidopsis mitochondrial inner membrane.

The $\mathrm{CcmB}$ protein is predicted to contain six transmembrane helices. Its sequence is highly conserved among all flowering plants, showing 93\% identity. The hydropathy profiles of plant and prokaryotic $\mathrm{CcmB}$ proteins are almost identical. In the wheat mitoplast fraction and in inner mitochon- 
drial membrane protein extracts antibodies recognize the CcmB polypeptide (Faivre-Nitschke et al., 2001). The most conserved motif DEDGS/TLEL of bacterial $\mathrm{CcmB}$ is thought to be oriented towards the matrix and to interact with the ATP-binding domain of ABC transporter. Rayapuram et al. (2007) - on the basis of in silico topology predictions - proposed that the plant $\mathrm{CcmB}$ protein contains six transmembrane helices, four matrix-facing loops and three IMS loops. Using the yeast two-hybrid assay they also showed that Arabidopsis $\mathrm{CcmB}$ interacts with CCMA by means of loops oriented toward the matrix. Interestingly, the plant $\mathrm{CcmB}$ protein contains seven conserved cysteine residues which are absent in bacterial $\mathrm{CcmB}$ proteins.

The proposed topology of bacterial CcmC proteins is generally the same as that of CcmB. E. coli CcmC has the conserved WWD motif found in the periplasmic loop between the third and the fourth transmembrane helix. CcmC from plant mitochondria is a conserved integral inner mitochondrial membrane protein, with at least 33\% hydrophobic residues (Bonnard \& Grienenberger, 1995). Raczynska et al. (2006) showed that the CcmC protein (24 $\mathrm{kDa}$ ) is present in Arabidopsis mitochondria and associated with the membrane, but not with the soluble fraction of mitochondria. These results support the localization predicted in silico.

The CcmE protein is one of the best characterized $\mathrm{Ccm}$ proteins. The soluble globular domain of this protein is anchored to the membrane by the helical region (Christensen et al., 2007). CcmE acts as a heme chaperone by transient covalent heme binding to the H130 residue. Stevens et al. (2003) and Uchida et al. (2004) showed that residues 30 and 134 of bacterial $\mathrm{CcmE}$ also play an important role in heme ligation to $\mathrm{CcmE}$ that is supported by structural data. The $\mathrm{CcmE}$ polypeptide was proposed to have a two-domain structure with a $\beta$-barrel core and an important, though not essential for the functioning, C-terminal domain which appears to be quite flexible (Enggist \& Thöny-Meyer, 2003; Enggist et al., 2003) and in general features resembles domains of iron or heme binding proteins (Baker et al., 2003).

The nuclear-encoded CCME protein is transported into Arabidopsis mitochondria using the N-terminal cleavable targeting sequence. The localization of the CCME protein in mitochondria of different land plants, besides Arabidopsis, has also been confirmed in cauliflower, turnip, rapeseed and radish (Spielewoy et al., 2001). Additionally, it was confirmed that Arabidopsis CCME is exposed on the outer face of the inner mitochondrial membrane (Spielewoy et al., 2001). It means that this protein is oriented towards the IMS. Plant mitochondrial CCME proteins display $35-40 \%$ identity with the Bradyrhizobium and E. coli homologous polypeptides.
Spielewoy et al. (2001) suggested that in some cases the plant and bacterial CCM proteins can be interchangeable because E. coli CcmC can donate heme to the Arabidopsis CCME. Unfortunately, due to the instability of purified Arabidopsis CCME protein, the heme binding to it cannot be tested easily.

So far no bacterial $\mathrm{CcmD}$ protein homologs have been found in plant material. Their genes have not been identified in the nuclear or mitochondrial genomes of higher plants until now. The C cmD protein of E. coli is a small polypeptide with 69 aminoacid residues. It strengthens the transient interactions between $\mathrm{CcmC}$ and $\mathrm{CcmE}$, forming the CcmCDE complex (Ahuja \& Thöny-Meyer, 2005). According to the recent speculations of Richard-Fogal et al. (2008), $\mathrm{CcmD}$ is also a candidate for the component of another complex CcmABCD. Those authors also provide experimental evidence for the presence of one transmembrane domain in $\mathrm{CcmD}$ and localization of the N-terminal domain outside and the C-terminal one inside the periplasmic membrane. Generally, one could speculate that plant $\mathrm{CcmC}$ and CCME proteins may compensate for the absence of $\mathrm{CcmD}$ making the CcmCE complex stable without the participation of a third CCM protein.

\section{Thiooxidation/thioreduction pathway}

In the best known bacterial systems several proteins are engaged in maintaining the thiooxidation/thioreduction balance of apocytochrome $c$. These are: the periplasmic thioredoxin-like $\mathrm{CcmG}$ protein, disulfide reductases such as $\mathrm{C} c \mathrm{mH}$ and DsbD, and components of the thiooxidation system - disulfide oxidases DsbA and DsbB (from disulfide bond formation protein). According to Reid et al. (2001), E. coli CcmG may play a role in the reduction of apocyt. $c$ at the very late stage of the $c$-type cytochrome assembly, that is prior to the heme attachment by $\mathrm{CmF}$ and $\mathrm{CcmH}$. In contrast to the bacterial periplasmic space, the mitochondrial IMS displays generally reductive properties. No orthologs of thioredoxin CcmG or Dsb oxidases have been detected until now in plant mitochondria and $\mathrm{CCMH}$ remains the main important component of the reducing pathway of SI identified in plant mitochondria (Meyer et al., 2005). There are only speculations about other unidentified components in plant mitochondria that have captured the functions of the bacterial C cmG and Dsb proteins. One of those candidates might be a mitochondrial FAD-depended Erv1-like sulfhydryl oxidase, whose orthologs have been identified not only in yeast and human, but also in A. thaliana mitochondrial IMS (Levitan et al., 2004). The plant enzyme (AtErv1) contains the CXXXXC motif in the C-terminal domain; that motif has some unique properties that 
play an important role in the dimerization of the A. thaliana oxidase. The substrate of AtErv1 is not known, but the substrate of the yeast Erv1 protein appeared to be Mia40 which oxidizes target proteins and drives their import into IMS (Hell, 2008). Could an Erv1-like oxidase and Mia40-like redoxdependent receptor proteins also be necessary for the formation of disulfide bonds in apocyt. $c$ in plant mitochondria, which would make CCMH important for their reduction?

E. coli $\mathrm{CcmH}$ is a fusion protein descending from two polypeptides. In Rhodobacter two separate polypeptides exist: $\mathrm{CcmH}_{\mathrm{Rc}}$ and $\mathrm{CcmI}$; however, in E. coli the C-terminal part of $\mathrm{CcmI}$ is fused to the homolog of $\mathrm{CcmH}_{\mathrm{Rc}^{\prime}}$ forming $\mathrm{CcmH}$ (Sanders et al., 2005). Moreover, Bradyrhizobium japonicum proteins $\mathrm{CycL}$ and $\mathrm{CycH}$ correspond to the N- and C-terminal part of the E. coli $\mathrm{CcmH}$ protein, respectively. The only known plant homolog of the E. coli $\mathrm{CcmH}$ polypeptide - the Arabidopsis nuclear-encoded $\mathrm{CCMH}$ protein - corresponds to its $\mathrm{N}$ - terminal part. $\mathrm{CcmH}$ exposes its redox-active site - the LRCXXCQ motif - to the periplasmic space. The plant protein does not contain an $\mathrm{N}$-terminal targeting sequence. Moreover, specific antibodies recognize the Arabidopsis $\mathrm{CCMH}$ protein whose molecular mass is larger than the calculated one $(17.9 \mathrm{kDa})$. The topological model of this polypeptide predicts the presence of an $\mathrm{N}$-terminal domain exposed to the $p$-side and the C-terminus exposed to the $n$-side of the inner mitochondrial membrane (Meyer et al., 2005). The plant mitochondrial CCMH protein contains a hydrophobic domain and an RCXXC motif facing IMS. Meyer et al. (2005) also showed that Arabidopsis CCMH protein homologs may reduce the $\mathrm{CXXCH}$ motif in a peptide that mimics apocyt. $c$. In that study, two-hybrid assays also showed interactions between Arabidopsis $\mathrm{CCMH}$ and cyt. $c$.
CCMH is an essential Arabidopsis housekeeping gene because the development of the homozygotic knockout embryo is stopped during the torpedo stage in insertion mutants. Interestingly, no obvious phenotype could be observed among heterozygotic plants in different stages of development; however, self-fertilized mutant plants heterozygous for the T-DNA insertion contained 25\% smaller and pale seeds in their siliques, with homozygotic for the T-DNA insertion knockout embryos (Meyer et al., 2005). Up to the now, the plant CCMH protein could be treated as the only identified component of the putative reducing pathway. Moreover, as it will be discussed in the chapter below, plant $\mathrm{CCMH}$ acts not only as apocyt. $c$ disulfide reductase, but most probably also assists in the process of heme ligation to the apoprotein and henceforth plays quite an important role within the plant mitochondrial SI (Meyer et al., 2005).

\section{Components of system I responsible for the heme lyase activity}

Very little data relates to the components of heme lyase and their activity is best described in bacterial SI. Initially, it was thought that the activity of prokaryotic HL was associated mainly with the $\mathrm{CcmF}$ protein containing the WWF motif. Yet recent findings indicate that the prokaryotic HL complex is also dependent on the activity of additional proteins. For instance, the 'core ligase' complex of Rhodobacter capsulatus is probably composed of $\mathrm{CcmF}$ and $\mathrm{CcmH}_{\mathrm{Rc}}$ polypeptides. The bacterial $\mathrm{CcmI}$ protein probably participates in this complex by bringing apocyt. $c$ to the ligation with heme (Sanders et al., 2005; 2007).

Recent experimental evidence indicates that the Arabidopsis mitochondrial CCMH protein overexpressed in E. coli co-immunoprecipitates with E. coli $\mathrm{CcmF}$; on the other hand, plant CCMH could not re-

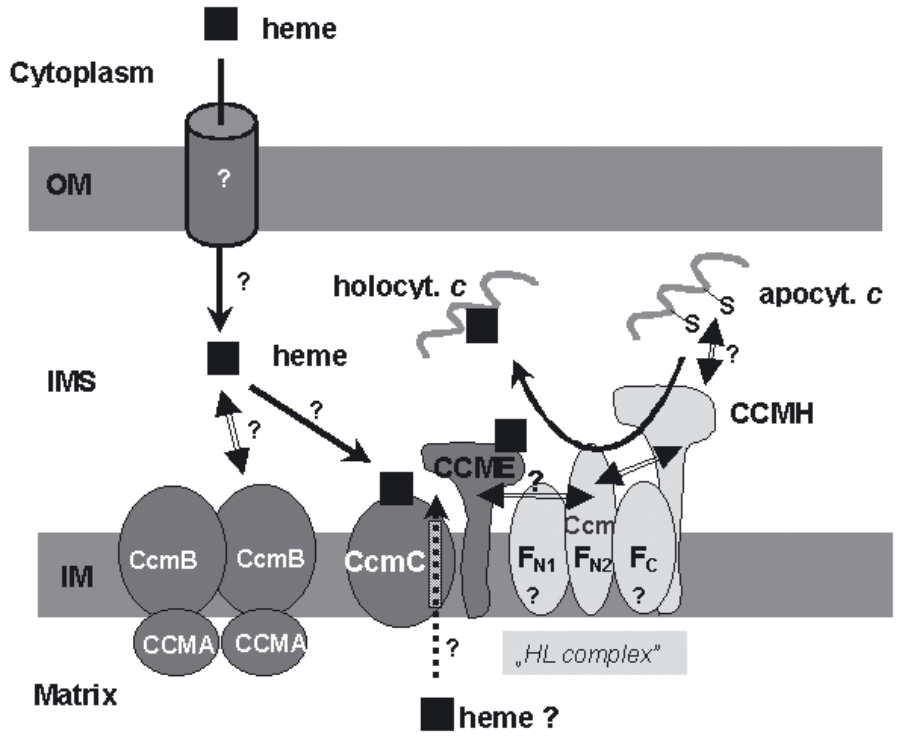

Figure 4. Model for system I of cyt. $c$ biogenesis and structure of HL complex in Arabidopsis mitochondria.

After Giegé et al. (2008), modified. Details are discussed in chapters: "Components of system I responsible for the heme lyase activity" and "Protein-heme and protein-protein interactions in the prokaryotic and in the plant mitochondrial system I". Currently favored hypothetical route of transport of the plastid-synthesized heme to mitochondria and heme delivery is shown by standard arrows with question marks. Alternative hypothetical route of transport of heme by CcmC from matrix to IMS is shown by dotted arrow with question mark. Proposed protein- protein interactions are shown as double-headed arrows. Some of them and the presence of $\mathrm{CcmF}_{\mathrm{N} 1}$ and $\mathrm{CcmF}_{\mathrm{C}}$ in the putative HL complex need to be verified experimentally (question marks). 
place its bacterial ortholog for holocyt. $c$ maturation in a complementation assay (Meyer et al., 2005).

It is worth noting that in Arabidopsis mitochondria, contrary to the situation in Brassica, two mitochondrial genes, $c c m F_{N 1}$ and $c c m F_{N 2}$ encode distinct $\mathrm{CcmF}_{\mathrm{N} 1}$ and $\mathrm{CcmF}_{\mathrm{N} 2}$ proteins. Moreover, the $\mathrm{CCMH}$ and $\mathrm{CcmF}_{\mathrm{N} 2}$ proteins which form a large 500-kDa membrane complex in Arabidopsis mitochondria, were proposed to hold the HL activity (Meyer et al., 2005). The Arabidopsis $\mathrm{CcmF}_{\mathrm{N} 2}$ protein is also present in an even larger complex $(700 \mathrm{kDa}$; Meyer et al., 2005). The identity and structure of the putative plant HL is still under debate. The proposed current model of plant HL is shown in Fig. 4.

Another protein that may be involved in HL activity in plant mitochondria, the $\mathrm{CcmF}_{\mathrm{C}}$ protein (50 kDa in wheat), is highly basic and hydrophobic (Giegé et al., 2004). In general the sequence of Cc$\mathrm{mF}_{\mathrm{C}}$ is highly conserved among plants species; nevertheless, it displays quite a low similarity to the C-terminal domain of $\mathrm{C} \mathrm{cmF}$ protein of Rhodobacter, Escherichia and Bradyrhizobium.

\section{PROTEIN-HEME AND PROTEIN-PROTEIN INTERACTIONS IN THE PROKARYOTIC AND IN THE PLANT MITOCHONDRIAL SYSTEM I}

As it was mentioned previously, the vast majority of data concerning SI comes from the study of prokaryotic models. The knowledge about how the proteins involved in this system operate in Prokaryota may be useful in the elucidation of the function of similar proteins in plant mitochondria. It is known that at least two E. coli proteins, $\mathrm{CcmC}$ and $\mathrm{CcmE}$, can interact directly with heme (Ren \& Thöny-Meyer, 2001). Due to the fact that CcmC displays high affinity for heme, direct transfer of heme to apocyt. $c$ may not be thermodynamically favored. It should be emphasized that a crucial step during the maturation of c-type cytochromes involves the transfer and the covalent attachment of heme to CcmE - the heme chaperone (Schulz et al., 1998). This step is followed by the heme transfer from $\mathrm{CcmE}$ to apocyt. $c$.

Ren and Thöny-Meyer (2001) showed that the direct interaction of $\mathrm{CcmC}$ with heme is not dependent on the presence of the WWD motif in $\mathrm{CcmC}$. This motif is necessary for the formation of the $\mathrm{C} c \mathrm{CE}$ complex and for the subsequent heme transfer from CcmC to CcmE. Additionally, Ahuja and Thöny-Meyer (2005) showed that the transient interactions between $\mathrm{CcmC}$ and $\mathrm{CcmE}$ could be significantly enhanced by CcmD.

The key role during initial steps of the maturation of bacterial $c$-type cytochromes may be played by $\mathrm{ABC}$ transporters with the proposed stoichiometry $\mathrm{CcmA}_{2} \mathrm{~B}_{1} \mathrm{C}_{1}$ (Feissner et al., 2006a; Fig. 5a). In the absence of $\mathrm{CcmA}$ or $\mathrm{CcmB}, \mathrm{CcmC}$ may form a stable complex with the heme-CcmE complex. The $\mathrm{CcmE}$ protein may be released from $\mathrm{CcmC}$ in an ATP-dependent manner only when the expression of $\mathrm{CcmA}$ and $\mathrm{CcmB}$ proteins facilitates the formation of the $\mathrm{CcmA}_{2} \mathrm{~B}_{1} \mathrm{C}_{1}$ complex (Feissner et al., 2006a). Those authors proposed that this complex may be treated as member of a novel subgroup of the $\mathrm{ABC}$ transporter family - the ABC heme release complex.

A different model of the participation of the $\mathrm{CcmAB}$ proteins in the maturation of $c$-type cytochromes in E. coli was suggested recently by Christensen et al. (2007; Fig. 5b). They argued with the results of Feissner et al. (2006a) concerning the composition and the proposed functional role of the $\mathrm{ABC}$ complex. In their opinion, $\mathrm{CcmC}$ may not represent a necessary component of this complex because $\mathrm{CcmA}$ is located in the cell membrane of E. coli only when $\mathrm{CcmB}$ is there. They presented experimental data that argue against the possible interaction of $\mathrm{CcmA}$ with both $\mathrm{CcmB}$ and $\mathrm{CcmC}$ within one complex. They pointed out that in fact no examples of complexes like $\mathrm{CcmA}_{2} \mathrm{~B}_{1} \mathrm{C}_{1}$ are known. The WWD motif, present in $\mathrm{CcmC}$, faces the periplasmic space; in contrast, highly conserved residues of $\mathrm{CcmB}$ are predicted to be present in cytoplasmic loops or within transmembrane domains. Moreover, $\mathrm{CcmC}$ could compensate for the lack of $\mathrm{CcmA}$ or $\mathrm{CcmB}$ and there is no detectable sequence similarity between $\mathrm{CcmB}$ and $\mathrm{CcmC}$, which would be expected if they were to interact with $\mathrm{CcmA}$. Christensen et al. (2007) also pointed out that CcmC seems to be generally an accesory protein in this complex, as this bacterial protein has probably additional functions, for instance in siderophore production. Additionally, $\mathrm{CcmA}$ cannot interact directly with $\mathrm{CcmC}$.

All these findings indicate that the composition of the $\mathrm{ABC}$ transporter and its participation in heme transport need to be further explored experimentally.

It is assumed that in E. coli, $\mathrm{CcmE}$ acts as a shuttle between the $\mathrm{CcmA}-\mathrm{CcmB}-\mathrm{CcmC}$ complex and a putative $\mathrm{HL}$ composed of two proteins: $\mathrm{CcmH}$ and CcmF (Ahuja \& Thöny-Meyer, 2003). Ren et al. (2002) also suggested that in E. coli SI, a stable interaction between $\mathrm{CcmF}, \mathrm{CcmE}$ and $\mathrm{CcmH}$ may take place without any involvement of apocyt. $c$.

It is still not clear how SI operates in the maturation of c-type cytochromes in plant mitochondria, as the way in which it causes the heme transport and delivery process is still not supported experimentally (Giegé et al., 2008). Moreover, the cellular localization of plant enzymes responsible for the last steps of heme biosynthesis is still under discussion (Tanaka \& Tanaka, 2007). For instance, there are strong suggestions for plastid (not mitochondrial) localization of coproporphyrinogen III oxidase 

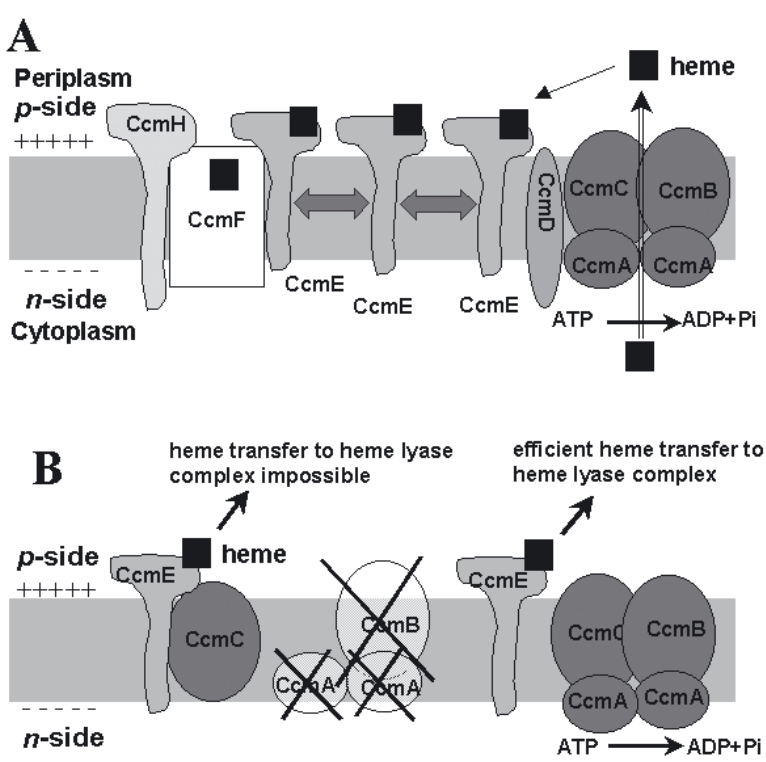

Feissner et al., 2006a

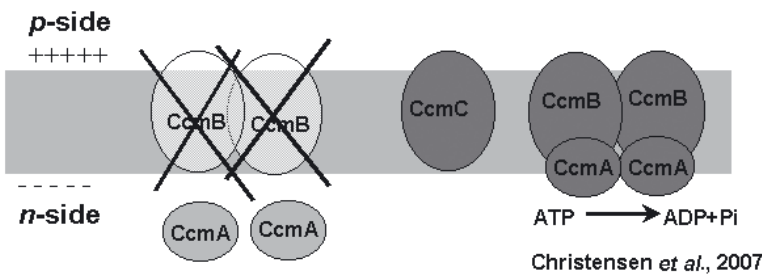

Figure 5. A. Transient interactions between $E$. coli $\mathrm{CcmE}$, the $A B C$ transporter complex and the putative HL. After Feissner et al. (2006a), modified. B. Models for the structure of the $\mathrm{ABC}$ transporter in $E$. coli maturation system of $c$-type cytochromes. The models are based on the data of Feissner et al. (2006a) and Christensen et al. (2007). Details concerning these two models are also described in chapter "Protein-heme and protein-protein interactions in the prokaryotic and in the plant mitochondrial SI".

According to Feissner et al. (2006a), the ABC transporter operating in heme transfer is composed of $\mathrm{CcmA}_{2} \mathrm{~B}_{1} \mathrm{C}_{1}$. When CcmA (containing ATP-binding cassette) and C cmB (containing the hexahelical transmembrane domain of the $\mathrm{ABC}$ transporter) proteins are present, they interact with $\mathrm{CcmC}$ (containing six transmembrane helices); therefore it is possible for heme to be transferred to the HL complex by CcmE. However, in the absence of $\mathrm{CcmA}$ and $\mathrm{CcmB}$, interactions of free $\mathrm{CcmC}$ with $\mathrm{CcmE}$ make the subsequent heme transfer impossible. The existence of such $\mathrm{ABC}$ transporter was challenged by Christensen et al. (2007). In their model CcmC acts independently of the transporter because in the absence of $\mathrm{CcmB}, \mathrm{CcmA}$ cannot be anchored to the membrane. Therefore, Christensen et al. (2007) conclude that $\mathrm{CcmC}$ cannot be a part of the ABC transporter, which is not involved in heme export.

(Santana et al., 2003) and protoporphyrin IX ferrochelatase (Lister et al., 2001; Cornah et al., 2002; Matsuda et al., 2003) coming from enzyme activity studies and targeting assays. However, there is still a possibility that some fraction of ferrochelatase or an unknown protein show low activity in plant mitochondria (Tanaka \& Tanaka, 2007). If ferrochelatase is present in plant mitochondrial matrix, one could imagine heme export to IMS by $\mathrm{CcmC}$, which - as was discussed earlier in the case of E. coli - could bind heme. If enzymes for the last steps of heme synthesis are absent from plant mitochondria, how is heme transported from plastids? No heme transporters have been identified in the plant mitochondrial OM. In that case $\mathrm{CcmC}$ and $\mathrm{CmAB}$ are not necessary for the heme import to IMS, but rather for the heme delivery to the putative HL (Giegé et al., 2008; Fig. 4).

The results of yeast two-hybrid analyses suggest that Arabidopsis mitochondrial CCMA protein, the product of the nuclear NAP10 gene, interacts with $\mathrm{CcmB}$ forming a rather distinct kind of $\mathrm{ABC}$ transporter. The transmembrane domains of this transporter are encoded in the mitochondrial genome, while its ATP-binding domains - in the nucleus (Rayapuram et al., 2007). The function of the plant CCMA-CcmB complex in the maturation pathway of cyt. $c$ remains to be elucidated.

The expression of both nuclear and mitochondrial genes coding for CCM proteins raises important questions about the key steps in coordination of the biogenesis of nuclear and mitochondrial CCM proteins as well as the formation of the CCM complexes present in plant mitochondria. The CCM complexes, assayed through the blue native electrophoresis, reveal different sizes. It has been shown for instance that Arabidopsis CCMA protein is present in a $480-\mathrm{kDa}$ complex that does not contain the $\mathrm{CCME}, \mathrm{CCMH}, \mathrm{CcmF}_{\mathrm{N} 1}, \mathrm{CcmF}_{\mathrm{N} 2}$ or $\mathrm{CcmF}_{\mathrm{C}}$ proteins (Rayapuram et al., 2007). On the other hand, $\mathrm{CCMH}$ and $\mathrm{CcmF}_{\mathrm{N} 2}$ are present in a $500-\mathrm{kDa}$ complex in Arabidopsis mitochondria (Meyer et al., 2005) and $\mathrm{CcmF}_{\mathrm{N} 2}$ together with $\mathrm{CcmF}_{\mathrm{C}}$ in a large $700-\mathrm{kDa}$ complex in wheat mitochondria (Giegé et al., 2004). No single complex containing all known CCM proteins has been detected in plant mitochondria yet and when the stoichiometry $\mathrm{CCMA}_{2}-\mathrm{CcmB}_{2}-\mathrm{CcmC}-\mathrm{CCME}-\mathrm{CcmF}_{\mathrm{N} 1}-\mathrm{CcmF}_{\mathrm{N} 2}-$ CCMH is considered, its size could still be calculated at about $300 \mathrm{kDa}$ only. These observations may suggest that: (1) at least some interactions between plant CCM proteins seem to be more stable than others; (2) different CCM proteins display different stoichiometry; (3) in mitochondria plantspecific CCM proteins may be present (Giegé et al., 2008) .

In Arabidopsis mitochondria, as revealed by blue native electrophoresis, the important interactions within the proposed HL would involve at least $\mathrm{CcmF}_{\mathrm{N} 2}$ and CCMH. As it was presented above, heterologously expressed Arabidopsis CCMH coimmunoprecipitates with bacterial $\mathrm{CcmF}$ (Meyer et al., 
2005). However, the interaction $\mathrm{CcmF}_{\mathrm{N} 2}-\mathrm{CCME}$ and the presence of $\mathrm{CcmF}_{\mathrm{N} 1}$ and $\mathrm{CcmF}_{\mathrm{C}}$ in the putative plant HL complex need to be verified (Giegé et al., 2008; Fig. 4).

The precise composition of complexes containing CCM proteins remains to be elucidated in detail. The way in which the different developmental stages and environmental conditions affect such interactions is completely unclear and has to be investigated, too.

\section{MATURATION OF PLASTID $c$-TYPE CYTOCHROMES}

The plant SII model has emerged from studies performed on chloroplasts of Chlamydomonas reinhardtii (Xie \& Merchant, 1996; Xie et al., 1998). Plant SII for the maturation of $c$-type cytochromes in plastids is represented by at least two protein homologs in Bacillus subtilis, namely ResB and ResC, which are known in plants as $\mathrm{C} \operatorname{cs} 1(\mathrm{Ccs} B)$ and $C \operatorname{cs} \mathrm{A}$, respectively. These proteins and the expression products of nuclear loci CCS2, CCS3 and CCS4 are postulated to form a hypothetical holocyt. $c$ assembly complex in Chlamydomonas plastids (Xie et al., 1998). The maturation pathway of plastid c-type cytochromes also requires $\mathrm{CcdA}$ and ResA proteins for the thiooxidation/thioreduction pathway. It should be stressed that some sequence motifs, as for example a tryptophane-rich motif, are present both in the components of SII - as the CcsA protein - and in the $\mathrm{CcmC}$ and $\mathrm{CcmF}$ proteins of SI.

Apocyt. $f$ having an N-terminal signal sequence, is synthesized on polysomes associated with the $n$-side of the thylakoid membrane. It is targeted to the $p$-side of the thylakoid membrane in a Secdependent way. According to Rothstein et al. (1985), a specific, trans-acting factor TCA1 is required for the translation of apocyt. $f$ in Chlamydomonas chloroplasts. 5' UTR of the petA transcript, encoding Chlamydomonas apocyt. $f$, autoregulates this process (Choquet et al., 1998).

Cyt. $c_{6}$ is translated as a precursor with a bipartite signal in the cytosol and is imported posttranslationally into the chloroplast. Its presequence does not contain the twin $\mathrm{R}$ motif that is characteristic for $\Delta \mathrm{pH}$-dependent protein import to thylakoids (Nakamoto et al., 2000).

\section{Heme transporting proteins}

Ccs proteins (from: cytochrome $\underline{c}$ synthesis) were discovered during the screening for defects in the maturation of plastid c-type cytochromes of Chlamydomonas reinhardtii non-photosynthetic and acetate-requiring mutants. It was shown that prod- ucts of four nuclear CCS and one chloroplast ( $\operatorname{Cs} A)$ loci are required for the heme attachment, but not for the apocytochrome processing during the assembly of holocyt. $f$ and $c_{6}$. The expression of Ccs genes in Chlamydomonas is under strict control (Xie \& Merchant, 1996; Inoue et al., 1997; Xie et al., 1998; Nakamoto et al., 2000). Essential roles in heme transport and in the chaperoning function in plastids were attributed to C cs1 and C csA proteins.

The ccsA gene is encoded by the chloroplast DNA of vascular plants, liverwort, red algae and cryptomonads (Hamel et al., 2003). According to in silico analyses, the Chlamydomonas CcsA protein (29 kDa, 320 amino acid-long) is a hydrophobic, thylakoid membrane protein with a few transmembrane regions. The CcsA protein contains three blocks of a conserved amino-acid sequence. The most conserved one is located in the C domain, specifically in the region containing the WWD motif (WGXXWXWDXXE). A comparison of 14 plastid and bacterial CcsA-like homologous sequences allowed identification of ten absolutely conserved residues in the conserved region that might form a putative active site. Bacterial CcsA protein is known to contain three more conserved residues H212, H309 and H347, that are necessary for the protein function (Hamel et al., 2003).

The $\cos \mathrm{A}$ gene rescues the photosynthetic deficiency in some Chlamydomonas mutant strains and restore the level of holocyt. $c_{6}$. The CcsA protein was proposed to be involved in heme binding and transport, by forming a heme channel in the thylakoid membrane.

Ccs1 is a membrane protein with three predicted transmembrane regions in the $\mathrm{N}$-terminal half of the protein and with hydrophilic C-terminal half of lumenal localization (Nakamoto et al., 2000). The C-terminal domain is important for the Ccs1 function; also a loop directed to the stroma seems to be essential for the activity of the protein. Additionally, a histidine residue located within the last transmembrane domain is absolutely required for the proper $c$-type cytochrome assembly. The predicted topology of Chlamydomonas Ccs1 protein resembles the topology of Synechocystis CcsB (Dreyfuss et al., 2003).

Plant Ccs1 protein could be immunodetected as a $60-\mathrm{kDa}$ polypeptide only in freshly prepared thylakoid membrane fraction and its accumulation increases with the growth of the Chlamydomonas culture between the log and the stationary phase. Css1 is also present in non-green plastids; however, after Chlamydomonas exposure to light, the abundances of Ccs1 and cytochrome $f$ increase in a parallel way. Although the accumulation of cyt. $f$ requires the Ccs1 function, the accumulation of Ccs1 is independent of cyt. $f$ during the light-initiated greening of etiolated cultures of Chlamydomonas (Dreyfuss et al., 2003). 
Ccs1 is considered to be a highly divergent protein (Dreyfuss et al., 2003). This may have resulted from its coevolution with the highly divergent apocytochromes.

The mutations of the Cos1 gene in the Chlamydomonas mutants studied could affect the level of transcript and protein accumulation. Nevertheless, nonsens mutations did not supress totally the protein pool in plastids. Interestingly, Ccs1 does not accumulate in $\operatorname{ccs} \mathrm{A}$ mutants; however, it is present after complementation of the same strain with the ccsA gene (Hamel et al., 2003). This phenomenon suggests the presence of a functional 'CCS' protein complex that is involved in heme transport and attachment in the thylakoid membrane. Such a complex, which was found in solubilized Chlamydomonas thylakoid membranes, may contain not only the Ccs1 and CcsA proteins but also other, unidentified components, as for instance products of the expression of nuclear loci CCS2-CCS4 (Xie et al., 1998; Dreyfuss et al., 2003; Hamel et al., 2003).

Summing up, the current working model of $c$-type cytochrome assembly in chloroplasts includes the chloroplast-encoded CcsA protein, the nucleusencoded Ccs1 polypeptide and possibly other, unidentified components. Heme is transferred to the thylakoid lumen from the stromal side with the participation of histidine residues and the WWD motif of CcsA and delivered to the ligation with reduced apocytochromes that are chaperoned by Ccs1.

\section{Thiol maintenance system in plastids}

Based on the components of the bacterial SII (BdbC, BdbD thiol oxidases, and ResA and CcdA proteins for thiol reduction), a similar system for maintaining thiols has been proposed to be present in the plastid compartment. CCDA and HCF164 (high chlorophyll fluorescence phenotype) are the best described plant homologs of bacterial CcdA and ResA proteins. However, no plastid orthologs of prokaryotic $\mathrm{BdbCD}$ proteins have been found yet. $\mathrm{Bdb}$ proteins are necessary for the proper folding and stability of disulfide bond-containing proteins participating in the transformation of B. subtilis (Meima et al., 2002).

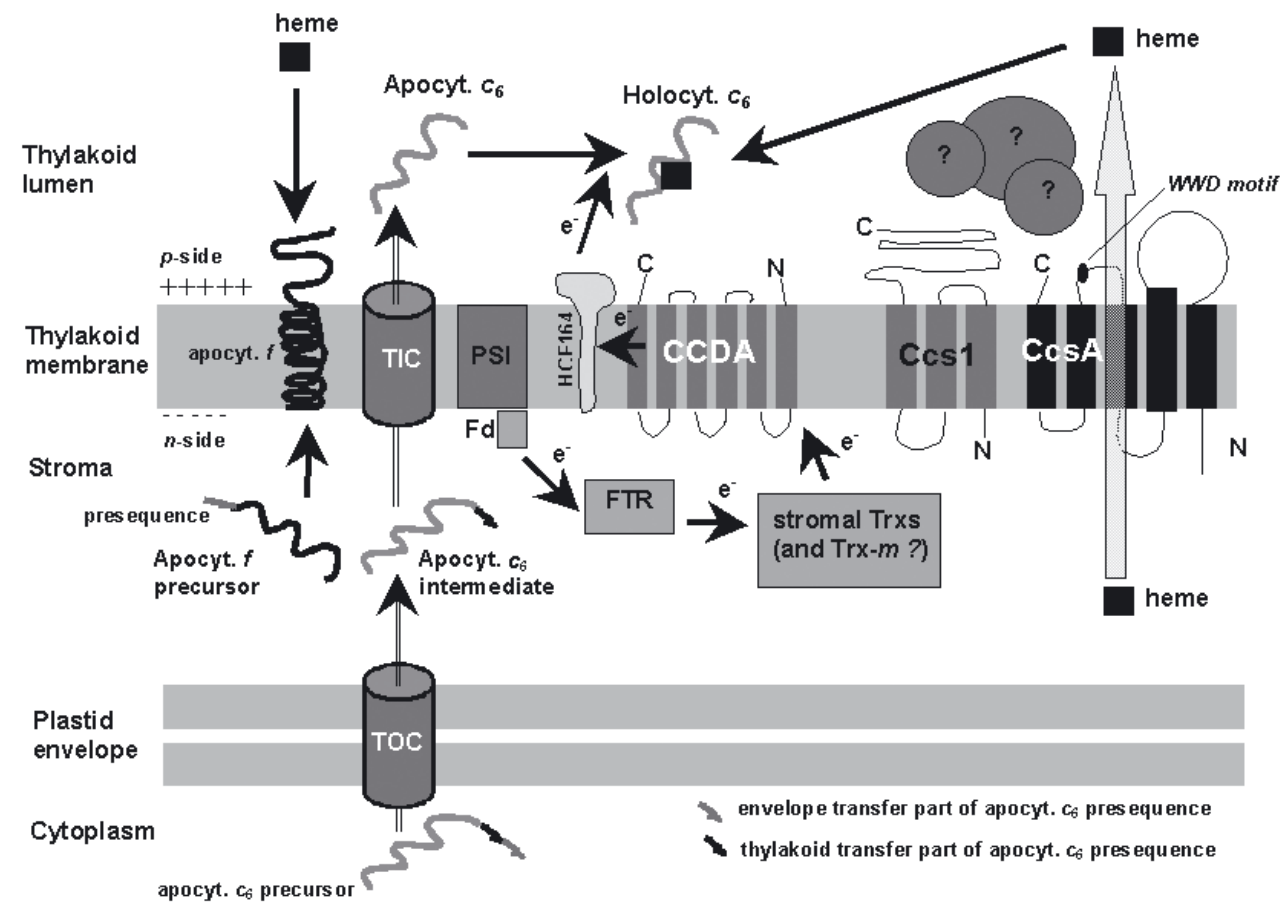

Figure 6. Model of system II for c-type cytochrome biogenesis in plastids based on data of Motohashi and Hisabori (2006), Page et al. (2004), Hamel et al. (2003) and Dreyfuss et al. (2003).

Detailed description of the system is given in chapter "Maturation of plastid $c$-type cytochromes". The model locates CcsA, Ccs1 as well as CCDA proteins in the thylakoid membrane. In addition to the channel-forming membrane proteins CcsA and Ccs1, some other factors were suggested to participate in heme transport across thylakoid membrane. The WWD motif is shown at the $p$-side domain of CcsA (black oval). Apocytochrome $c_{6}$, encoded in the nucleus, is probably transported by TOC/TIC complex, whereas apocytochrome $f$, encoded in chloroplast DNA, is directly inserted into the thylakoid membrane. Ferredoxin donates electrons to the ferredoxin-dependent thioredoxin reductase (FTR). FTR reduces stromal thioredoxins. The thioredoxin Trx- $m$ is a putative source of reducing equivalent at $n$-side, whereas HCF164 plays such a role at $p$-side of the thylakoid membrane. Two presequence parts for import of apocyt. $c_{6}$ are shown. 
Generally, in the thiooxidation/thioreduction pathway in plastids (Fig. 6) the thiol-reducing equivalents are proposed to be transferred from the $n$-side to the $p$-side of the thylakoid membrane. For the reduction of $c$-type apocytochrome both thioredoxins and thioredoxin-like proteins are necessary. A currently preferred candidate for the source of reducing equivalents at the $n$-side is an $m$-type thioredoxin (Motohashi \& Hisabori, 2006). This type of thioredoxins can transfer electrons to the lumenal HCF164 protein across the thylakoid membrane. The thiooxidation/thioreduction pathway also contains CCDA and the HCF164 protein, a homolog of the $B$. subtilis ResA protein, a putative candidate for the $p$-side transducer of reducing equivalents (Page et al., 2004). Plastid CCDA, being the homolog of the bacterial protein $\mathrm{CcdA}$, resembles the central part of DipZ/DsbD proteins which are necessary for transmembrane thiol redox metabolism in bacterial systems (Katzen et al., 2002). CCDA is a polytopic membrane protein delivering the reducing equivalents to apocyt. $f$ prior to its conversion to the holocytochrome. It contains six transmembrane regions and a 141 amino acid-long $\mathrm{N}$-terminal extension functioning as a targeting sequence. Both the $\mathrm{N}$ - and C-terminal protein domains face the lumenal side of plastids (Page et al., 2004). The bacterial CcdA protein also contains in its transmembrane domain two conservative cysteines that are indispensable for functioning. In the chloroplast genome of Porphyra purpurea CCDA is encoded by the single gene that is linked to the ORF of a Ccs1-like protein. Page et al. (2004) showed that Arabidopsis CCDA could be targeted to pea chloroplasts. Other CcdA-like protein genes and their respective cDNAs have been identified in a variety of plants (rhodophyte algae Porphyra purpurea and angiosperms: Descurainia sophia, Glycine max, Hordeum vulgare, Lotus japonicus, Medicago truncatula) - without experimental determination of the cellular localization of their protein products, though.

HCF164 is a membrane-anchored $29 \mathrm{kDa}$ protein (261 amino acid-long) with a disulfide-reductase activity and its active site facing the $p$-side of the membrane. HCF164 displays some similarity to the eubacterial $\mathrm{Ccs} X$ and $\mathrm{CcmG}$ proteins. It appeared that recombinant HCF164 protein depleted of the first 115 amino-acid residues reduces disulfide bonds between insulin chains; yet this reduction activity is twice lower compared to the action of the purified thioredoxin protein (Lennartz et al., 2001).

The plastid HCF164 protein contains at least three domains; the second domain is characterized as hydrophobic, while the third, large domain is hydrophilic. The first two domains contain regions sharing some features of plastid transit peptides; therefore, it is believed that the HCF164 protein is anchored in the thylakoid membrane by the $\mathrm{N}$-terminal domain (Lennartz et al., 2001). The Cterminal domain, which faces the lumenal side of thylakoid, as it was shown in a protease protection assay carried out by Motohashi and Hisabori (2006), contains a WCXXC motif typical of the thioredoxin active site.

Recently, Lennartz et al. (2006) also showed that another protein - HCF153 (15 kDa), containing a chloroplast transit peptide, is tightly bound to the thylakoid membrane. HCF153 probably participates in a post-translational step of biogenesis of cytochrome $b_{6} f$ complex. Hence, HCF153 may be regarded as another protein necessary for the biogenesis of $c$-type cytochromes in plastids.

Plant nuclear genomes encode numerous isoforms of thioredoxins which may also be active in plastids (Balmer et al., 2003). To identify the activity of redox-linked proteins in thylakoids, Balmer et al. (2006) applied a new experimental approach based on the monobromobimane fluorescent thiol probe. They discovered fourteen potential thioredoxins, which were bound to the membrane. Summarizing, it is tempting to speculate that in the future new data might help in the discovery of other thioredoxins or disulfide reductases required for the maturation of plastid c-type cytochromes.

\section{CONCLUDING REMARKS}

In the light of the data presented above the experimental validation of the functioning of the $c$-type cytochrome maturation process in plant mitochondria and in higher-plant plastids is still insufficient. The progress in characterization of plant organellar proteomes may be helpful in the identification of novel proteins that assist in the biogenesis of c-type cytochromes. The growing understanding among researches of how bacterial system I was "adopted" by plant mitochondria could also accelerate the identification of unknown components of this maturation pathway (Giegé et al., 2004).

The plant mitochondrial system I appears to be functionally more complex than any other system known. System II, which seems to be designed for the biogenesis of plastid c-type cytochromes, may also contain - as yet - unidentified components. It should be added that the general view about the maturation pathways of cytochrome $c$ in plant organelles may in the future depend on the recognition and characterization of proteins involved in other biological processes; moreover, it has been suggested lately that some CCM proteins may indeed perform different biological functions 
being directly or indirectly involved in them (Cianciotto et al., 2005).

\section{Acknowledgements:}

This work was supported by a post-doctoral fellowship for M.R. from the Foundation for Polish Science (in 2004) and by the European Union Marie Curie Host Fellowship for the Transfer of Knowledge (No. MTKD-CT-2004-517068) for the post-doctoral stay of M.R. at the Institute of Plant Molecular Biology (IBMP-CNRS, Strasbourg, France) in 2006.

\section{REFERENCES}

Ahuja U, Thöny-Meyer L (2003) Dynamic features of a heme delivery system for cytochrome $c$ maturation. J Biol Chem 278: 52061-52070.

Ahuja U, Thöny-Meyer L (2005) CcmD is involved in complex formation between $\mathrm{CcmC}$ and the heme chaperone $\mathrm{CcmE}$ during cytochrome $c$ maturation. J Biol Chem 280: 236-243.

Allen JWA, Ferguson SJ (2006) What is the substrate specificity of the System I cytochrome $c$ biogenesis apparatus? Bioch Soc Trans 34: 150-151.

Allen JWA, Daltrop O, Stevens JM, Ferguson SJ (2003) cType cytochromes: diverse structures and biogenesis systems pose evolutionary problems. Phil Trans $R$ Soc Lond B 358: 255-266.

Allen JWA, Ginger ML, Ferguson SJ (2004a) Complexity and diversity in c-type cytochrome biogenesis systems. Bioch Soc Trans 33: 145-146.

Allen JWA, Ginger ML, Ferguson SJ (2004b) Maturation of the unusual single-cysteine $(\mathrm{XXXCH})$ mitochondrial $c$ type cytochromes found in trypanosomatids must occur through a novel biogenesis pathway. Biochem J 383: 537-542.

Allen JWA, Harvat EM, Stevens JM, Ferguson SJ (2006) A variant system I for cytochrome $c$ biogenesis in archaea and some bacteria has a novel $\mathrm{CcmE}$ and no $\mathrm{CcmH}$. FEBS Lett 580: 4827-4834.

Allen JWA, Jackson AP, Rigden DJ, Willis AC, Ferguson SJ, Ginger ML (2008) Order within a mosaic distribution of mitochondrial c-type cytochrome biogenesis systems? FEBS J 275: 2385-2402.

Baker HM, Anderson BF, Baker EN (2003) Dealing with iron: common structural principles in proteins that transport iron and heme. Proc Natl Acad Sci USA 100: 3579-3583.

Balmer Y, Koller A, del Val G, Manieri W, Schürmann P, Buchanan BB (2003) Proteomics gives insight into the regulatory function of chloroplast thioredoxins. Proc Natl Acad Sci 100: 370-375.

Balmer Y, Vensel WH, Hurkman WJ, Buchanan BB (2006) Thioredoxin target proteins in chloroplast thylakoid membranes. Antioxid Redox Signal 8: 1829-1834.

Beckman DL, Trawick DR, Kranz RG (1992) Bacterial cytochromes $c$ biogenesis. Genes Dev 6: 268-283.

Bernard DG, Gabilly ST, Dujardin G, Merchant S, Hamel PP (2003) Overlapping specificities of the mitochondrial cytochrome $c$ and $c_{1}$ heme lyases. J Biol Chem 278: 49732-49742.

Bernard DG, Quevillon-Cheruel S, Merchant S, Guiard B, Hamel PP (2005) Cyc2p, a membrane-bound flavopro- tein involved in the maturation of mitochondrial c-type cytochromes. J Biol Chem 280: 39852-39859.

Bonnard G, Grienenberger JM (1995) A gene proposed to encode a transmembrane domain of an ABC transporter is expressed in wheat mitochondria. Mol Gen Genet 246: 91-99.

Choquet Y, Stern DB, Wostrikoff K, Kuras R, Girard-Bascou J, Wollman F-A (1998) Translation of cytochrome $f$ is autoregulated through the $5^{\prime}$ untranslated region of petA mRNA in Chlamydomonas chloroplasts. Proc Natl Acad Sci USA 95: 4380-4385.

Christensen O, Harvat EM, Thöny-Meyer L, Ferguson SJ, Stevens JM (2007) Loss of ATP hydrolysis activity by $\mathrm{Ccm} A B$ results in loss of $c$-type cytochrome synthesis and incomplete processing of CcmE. FEBS J 274: 23222332.

Cianciotto NP, Cornelis P, Baysse C (2005) Impact of the bacterial type I cytochrome $c$ maturation system on different biological processes. Mol Microbiol 56: 1408-1415.

Clifton SW, Minx P, Fauron CMR, Gibson M, Allen JO, Sun H, Thompson M, Barbazuk WB, Kanuganti S, Tayloe C, Meyer L, Wilson RK, Newton KJ (2004) Sequence and comparative analysis of the maize NB mitochondrial genome. Plant Physiol 136: 3486-3503.

Cook GM, Poole RK (2000) Oxidase and periplasmic cytochrome assembly in Escherichia coli K-12: CydDC and $\mathrm{Ccm} A \mathrm{~B}$ are not required for haem-membrane association. Microbiology 146: 527-536.

Cornah JE, Roper JM, Pal Singh D, Smith AG (2002) Measurement of ferrochelatase activity using a novel assay suggests that plastids are the major site of haem biosynthesis in both photosynthetic and nonphotosynthetic cells of pea (Pisum sativum L.). Biochem J 362: 423-432.

Diekert K, de Kroon AIPM, Ahting U, Niggemeyer B, Neupert W, de Kruijff B, Lill R (2001) Apocytochrome c requires the TOM complex for translocation across the mitochondrial outer membrane. EMBO J 20: 5626-5635.

Dreyfuss BW, Hamel PP, Nakamoto SS, Merchant S (2003) Functional analysis of a divergent system II protein, Ccs1, involved in c-type cytochrome biogenesis. J Biol Chem 278: 2604-2613.

Enggist E, Thöny-Meyer L (2003) The C-terminal flexible domain of the heme chaperone CcmE is important but not essential for its function. J Bacteriol 185: 3821-3827.

Enggist E, Schneider MJ, Schulz H, Thöny-Meyer L (2003) Biochemical and mutational characterization of the heme chaperone $\mathrm{CcmE}$ reveals a heme binding site. $J$ Bacteriol 185: 175-183.

Faivre-Nitschke SE, Nazoa P, Gualberto JM, Grienenberger JM, Bonnard G (2001) Wheat mitochondria $c \mathrm{cmB}$ encodes the membrane domain of a putative ABC transporter involved in cytochrome $c$ biogenesis. Biochim Biophys Acta 1519: 199-208.

Feissner RE, Richard-Fogal CL, Frawley ER, Kranz RG (2006a) ABC transporter-mediated release of a haem chaperone allows cytochrome $c$ biogenesis. Mol Microbiol 61: 219-231.

Feissner RE, Richard-Fogal CL, Frawley ER, Loughman JA, Earley KW, Kranz RG (2006b) Recombinant cytochromes $c$ biogenesis systems I and II and analysis of haem delivery pathways in Escherichia coli. Mol Microbiol 60: 563-577.

Ferguson SJ (2001) Keilin's cytochromes: how bacteria use them, vary them and make them. Bioch Soc Trans 29: 629-640.

Giegé P, Brennicke A (1999) RNA editing in Arabidopsis mitochondria effects $441 \mathrm{C}$ to $\mathrm{U}$ changes in ORFs. Proc Natl Acad Sci USA 96: 15324-15329. 
Giegé P, Rayapuram N, Meyer EH, Grienenberger J-M, Bonnard G (2004) $\mathrm{CcmF}_{\mathrm{C}}$ involved in cytochrome $c$ maturation is present in a large sized complex in wheat mitochondria. FEBS Lett 563: 165-169.

Giegé P, Grienenberger JM, Bonnard G (2008) Cytochrome $c$ biogenesis in mitochondria. Mitochondrion 8: 61-73.

Goldman BS, Kranz RG (2001) ABC transporters associated with cytochrome $c$ biogenesis. Res Microbiol 152: 323-329.

Goldman BS, Beck DL, Monika EM, Kranz RG (1998) Transmembrane heme delivery systems. Proc Natl Acad Sci USA 95: 5003-5008.

Gonzalez DH, Bonnard G, Grienenberger J-M (1993) A gene involved in the biogenesis of cytochromes is cotranscribed with a ribosomal protein gene in wheat mitochondria. Curr Genet 24: 248-255.

Hamel PP, Dreyfuss BW, Xie Z, Gabilly ST, Merchant S (2003) Essential histidine and tryptophan residues in CcsA, a system II polytopic cytochrome $c$ biogenesis protein. J Biol Chem 278: 2593-2603.

Handa H (2003) The complete nucleotide sequence and RNA editing content of the mitochondrial genome of rapeseed (Brassica napus L.): comparative analysis of the mitochondrial genomes of rapeseed and Arabidopsis thaliana. Nucleic Acids Res 31: 5907-5916.

Handa H, Bonnard G, Grienenberger J-M (1996) The rapeseed mitochondrial gene encoding a homologue of the bacterial protein Ccl1 is divided into two independently transcribed reading frames. Mol Gen Genet 252: 292-302.

Hazle T, Bonen L (2007) Comparative analysis of sequences preceding protein-coding mitochondrial genes in flowering plants. Mol Biol Evol 24: 1101-1112.

Hell K (2008) The Erv1-Mia40 disulfide relay system in the IMS of mitochondria. Biochim Biophys Acta 1783: 601-609.

Howe CJ, Schlarb-Ridley BG, Wastl J, Purton S, Bendall DS (2006) The novel cytochrome $c_{6}$ of chloroplasts: a case of evolutionary bricolage ? J Exp Bot 57: 13-22.

Inoue K, Dreyfuss BW, Kindle KL, Stern DB, Merchant S, Sodeinde OA (1997) Ccs1, a nuclear gene required for the post-translational assembly of chloroplast c-type cytochromes. J Biol Chem 272: 31747-31754.

Jekabsons W, Schuster W (1995) orf250 encodes a second subunit of an ABC-type heme transporter in Oenothera mitochondria. Mol Gen Genet 246: 166-173.

Katzen F, Deshmukh M, Daldal F, Beckwith J (2002) Evolutionary domain fusion expanded the substrate specificity of the transmembrane electron transporter DsbD. EMBO J 21: 3960-3969.

Kranz R, Lill R, Goldman B, Bonnard G, Merchant S (1998) Molecular mechanisms of cytochrome $c$ biogenesis: three distinct systems. Mol Microbiol 29: 383-396.

Kubo T, Nishizawa S, Sugawara A, Itchoda N, Estiati A, Mikami T (2000) The complete nucleotide sequence of the mitochondrial genome of sugar beet (Beta vulgaris L.) reveals a novel gene for $\mathrm{RNA}^{\mathrm{Cys}}$ (GCA). Nucleic Acids Res 28: 2571-2576.

Lang BF, Burger G, O'Kelly CJ, Cedergren R, Golding GB, Lemieux C, Sankoff D, Turmel M, Gray MW (1997) An ancestral mitochondrial DNA resembling a eubacterial genome in miniature. Nature 387: 493-497.

Lee J-H, Harvat EM, Stevens JM, Ferguson SJ, Saier Jr MH (2007) Evolutionary origins of members of a superfamily of integral membrane cytochrome $c$ biogenesis proteins. Biochim Biophys Acta 1768: 2164-2181.

Lennartz K, Plücken H, Seidler A, Westhoff P, Bechtold N, Meierhoff K (2001) HCF164 encodes a thioredoxin-like protein involved in the biogenesis of the cytochrome $b_{6} f$ complex in Arabidopsis. Plant Cell 13: 2539-2551.

Lennartz K, Bossmann S, Westhoff P, Bechtold N, Meierhoff K (2006) HCF153, a novel nuclear-encoded factor necessary during a post-translational step in biogenesis of the cytochrome $b_{6} f$ complex. Plant J 45: 101-112.

Levitan A, Danon A, Lisowsky T (2004) Unique features of plant mitochondrial sulfhydryl oxidase. J Biol Chem 279: 20002-20008.

Lister R, Chew O, Rudhe C, Lee M-N, Whelan J (2001) Arabidopsis thaliana ferrochelatase-I and -II are not imported into Arabidopsis mitochondria. FEBS Lett 506: 291-295.

Masuda T, Suzuki T, Shimada H, Ohta H, Takamiya K (2003) Subcellular localization of two types of ferrochelatase in cucumber. Planta 217: 602-609.

Meima R, Eschevins C, Fillinger S, Bolhuis A, Hamoen LW, Dorenbos R, Quax WJ, van Dijl JM, Provvedi R, Chen I, Dubnau D, Bron S (2002) The bdbDC operon of Bacillus subtilis encodes thiol-disulfide oxidoreductases required for competence development. J Biol Chem 277: 6994-7001.

Menassa R, El-Rouby N, Brown GG (1997) An open reading frame for a protein involved in cytochrome $c$ biogenesis is split into two parts in Brassica mitochondria. Curr Genet 31: 70-79.

Meyer EH, Giegé P, Gelhaye E, Rayapuram N, Ahuja U, Thöny-Meyer L, Grienenberger J-M, Bonnard G (2005) AtCCMH, an essential component of the c-type cytochrome maturation pathway in Arabidopsis mitochondria, interacts with apocytochrome c. Proc Natl Acad Sci 102: 16113-16118.

Motohashi K, Hisabori T (2006) HCF164 receives reducing equivalents from stromal thioredoxin across the thylakoid membrane and mediates reduction of target proteins in the thylakoid lumen. J Biol Chem 281: 35039-35047.

Nakamoto SS, Hamel P, Merchant S (2000) Assembly of chloroplast cytochromes $b$ and c. Biochimie 82: 603-614.

Nicholson DW, Stuart RA, Neupert W (1989) Biogenesis of cytochrome $c_{1}$. Role of cytochrome $c_{1}$ heme lyase and of the two proteolytic processing steps during import into mitochondria. J Biol Chem 264: 10156-10168.

Notsu Y, Masood S, Nishikawa T, Kubo N, Akiduki G, Nakazono M, Hirai A, Kadowaki K (2002) The complete sequence of the rice (Oryza sativa L.) mitochondrial genome: frequent DNA sequence acquisition and loss during the evolution of flowering plants. Mol Gen Genomics 268: 434-445.

Oda K, Yamato K, Ohta E, Nakamura Y, Takemura M, Nozato N, Akashi K, Kanegae T, Ogura Y, Kohchi T, Ohyama K (1992) Gene organization deduced from the complete sequence of liverwort Marchantia polymorpha mitochondrial DNA. A primitive form of plant mitochondrial genome. J Mol Biol 223: 1-7.

Ogihara Y, Yamazaki Y, Murai K, Kanno A, Terachi T, Shiina T, Miyashita N, Nasuda S, Nakamura C, Mori N, Takumi S, Murata M, Futo S, Tsunewaki K (2005) Structural dynamics of cereal mitochondrial genomes as revealed by complete nucleotide sequencing of the wheat mitochondrial genome. Nucleic Acids Res 33: 6235-6250.

Ohta N, Sato N, Kuroiwa T (1998) Structure and organization of the mitochondrial genome of the unicellular red alga Cyanidioschyzon merolae deduced from the complete nucleotide sequence. Nucleic Acids Res 26: 5190-5198.

Page MLD, Hamel PP, Gabilly ST, Zegzouti H, Perea JV, Alonso JM, Ecker JR, Theg SM, Christensen SK, Merchant S (2004) A homolog of prokaryotic thiol disulfide 
transporter $\mathrm{Ccd} A$ is required for the assembly of the cytochrome $b_{6} f$ complex in Arabidopsis chloroplasts. J Biol Chem 279: 32474-32482.

Quinn JM, Barraco P, Eriksson M, Merchant S (2000) Coordinate copper- and oxygen-responsive $C y c 6$ and $C p x 1$ expression in Chlamydomonas is mediated by the same element. J Biol Chem 275: 6080-6089.

Raczynska KD, Le Ret M, Rurek M, Bonnard G, Augustyniak H, Gualberto JM (2006) Plant mitochondrial genes can be expressed from mRNAs lacking stop codons. FEBS Lett 580: 5641-5646.

Ramseier TM, Winteler HV, Hennecke H (1991) Discovery and sequence analysis of bacterial genes involved in the biogenesis of c-type cytochromes. J Biol Chem 266: 7793-7803.

Rayapuram N, Hagenmuller J, Grienenberger J-M, Giegé P, Bonnard G (2007) AtCCMA interacts with AtCCMB to form a novel mitochondrial $\mathrm{ABC}$ transporter involved in cytochrome $c$ maturation in Arabidopsis. J Biol Chem 282: 21015-21023.

Reid E, Cole J, Eaves DJ (2001) The Escherichia coli CcmG protein fulfils a specific role in cytochrome $c$ assembly. Biochem J 355: 51-58.

Ren Q, Thöny-Meyer L (2001) Physical interaction of CcmC with heme and the heme chaperone $\mathrm{CcmE}$ during cytochrome $c$ maturation. J Biol Chem 276: 32591-32596.

Ren Q, Ahuja U, Thöny-Meyer L (2002) A bacterial cytochrome $c$ heme lyase. $\mathrm{CcmF}$ forms a complex with the heme chaperone $\mathrm{CcmE}$ and $\mathrm{CcmH}$ but not with apocytochrome c. I Biol Chem 277: 7657-7663.

Richard-Fogal CL, Frawley ER, Feissner RE, Kranz RG (2007) Heme concentration dependence and metalloporphyrin inhibition of the system I and II cytochrome $c$ assembly pathways. J Bacteriol 189: 455-463.

Richard-Fogal CL, Frawley ER, Kranz RG (2008) Topology and function of $\mathrm{CcmD}$ in cytochrome $c$ maturation. J Bacteriol 190: 3489-3493.

Rothstein SJ, Gatenby AA, Willey DL, Gray JC (1985) Binding of pea cytochrome $f$ to the inner membrane of Escherichia coli requires the bacterial $\sec A$ gene product. Proc Natl Acad Sci USA 82: 7955-7959.

Sanders C, Deshmukh M, Astor D, Kranz RG, Daldal F (2005) Overproduction of $\mathrm{CcmG}$ and $\mathrm{CcmFH}_{\mathrm{Rc}}$ fully supress the $c$-type cytochrome biogenesis defect of Rhodobacter capsulatus CcmI-null mutants. I Bacteriol 187: 4245-4256.

Sanders C, Boulay C, Daldal F (2007) Membrane-spanning and periplasmic segments of $\mathrm{CcmI}$ have distinct functions during cytochrome $c$ biogenesis in Rhodobacter capsulatus. J Bacteriol 189: 789-800.

Santana MA, Tan FC, Smith AG (2002) Molecular characterization of coproporphyrinogen oxidase from Glycine max and Arabidopsis thaliana. Plant Physiol Biochem 40: 289-298.

Schulz H, Hennecke H, Thöny-Meyer L (1998) Prototype of a heme chaperone essential for cytochrome $c$ maturation. Science 281: 1197-1200.

Schuster W (1994) The highly edited orf206 in Oenothera mitochondria may encode a component of a heme transporter involved in cytochrome $c$ biogenesis. Plant Mol Biol 25: 33-42.

Schuster W, Combettes B, Flieger K, Brennicke A (1993) A plant mitochondrial gene encodes a protein involved in cytochrome $c$ biogenesis. Mol Gen Genet 239: 49-57.

Spielewoy N, Schulz H, Grienenberger J-M, Thöny-Meyer L, Bonnard G (2001) CCME, a nuclear-encoded hemebinding protein involved in cytochrome $c$ maturation in plant mitochondria. J Biol Chem 276: 5491-5497.

Steiner H, Kispal G, Zollner A, Haid A, Neupert W, Lill R (1996) Heme binding to a conserved Cys-Pro-Val motif is crucial for the catalytic function of mitochondrial heme lyases. J Biol Chem 271: 32605-32611.

Stevens JM, Daltrop O, Higham CW, Ferguson SJ (2003) Interaction of heme with variants of the heme chaperone CcmE carrying active site mutations and a cleavable N-terminal His tag. J Biol Chem 278: 20500-20506.

Stevens JM, Daltrop O, Allen JWA, Ferguson SJ (2004) cType cytochrome formation: chemical and biological enigmas. Acc Chem Res 37: 999-1007.

Sugiyama Y, Watase Y, Nagase M, Makita N, Yagura S, Hirai A, Sugiura M (2005) The complete nucleotide sequence and multipatite organization of the tobacco mitochondrial genome: comparative analysis of mitocondrial genomes in higher plants. Mol Gen Genomics 272: 603-615.

Tanaka R, Tanaka A (2007) Tetrapyrrole biosynthesis in higher plants. Annu Rev Plant Biol 58: 321-346.

Thöny-Meyer L, Fischer F, Künzler P, Ritz D, Hennecke H (1995) Escherichia coli genes required for cytochrome $c$ maturation. J Bacteriol 177: 4321-4326.

Turkarslan S, Sanders C, Daldal F (2006) Extracytoplasmic prosthetic group ligation to apoproteins: maturation of c-type cytochromes. Mol Microbiol 60: 537-541.

Walker JE, Saraste M, Runswick MJ, Gay NJ (1982) Distantly related sequences in the $\alpha$ - and $\beta$-subunits of ATP synthase, myosin, kinases and other ATP-requiring enzymes and a common nucleotide binding fold. EMBO J 1: 945-951.

Weigel M, Pesaresi P, Leister D (2003) Tracking the function of the cytochrome $c_{6}$-like protein in higher plants. Trends Plant Sci 8: 513-517.

Uchida T, Stevens JM, Daltrop O, Harvat EM, Hong L, Ferguson SJ, Kitagawa T (2004) The interaction of covalently bound heme with the cytochrome $c$ maturation protein CcmE. J Biol Chem 279: 51981-51988.

Unseld M, Marienfeld JR, Brandt P, Brennicke A (1997) The mitochondrial genome of Arabidopsis thaliana contains 57 genes in 366,926 nucleotides. Nat Genet 15: 57-61.

Xie Z, Merchant S (1996) The plastid-encoded $\operatorname{ccs} A$ gene is required for heme attachment to chloroplast $c$-type cytochrome cytochromes. I Biol Chem 271: 4632-4639. Xie Z, Culler D, Dreyfuss BW, Kuras R, Wollman FA, Girard-Bascou J, Merchant S (1998) Genetic analysis of chloroplast c-type cytochrome assembly in Chlamydomonas reinhardtii: one chloroplast locus and at least four nuclear loci are required for heme attachment. Genetics 148: 681-692. 